\title{
Three-dimensional spatial structure of the macro-pores and flow simulation in anthracite coal based on X-ray $\mu$-CT scanning data
}

\author{
Hui-Huang Fang ${ }^{1,2} \cdot$ Shu-Xun Sang ${ }^{1,2} \cdot$ Shi-Qi Liü
}

Received: 1 March 2019 / Published online: 12 August 2020

(c) The Author(s) 2020

\begin{abstract}
The three-dimensional (3D) structures of pores directly affect the $\mathrm{CH}_{4}$ flow. Therefore, it is very important to analyze the 3D spatial structure of pores and to simulate the $\mathrm{CH}_{4}$ flow with the connected pores as the carrier. The result shows that the equivalent radius of pores and throats are $1-16 \mu \mathrm{m}$ and $1.03-8.9 \mu \mathrm{m}$, respectively, and the throat length is 3.28-231.25 $\mu \mathrm{m}$. The coordination number of pores concentrates around three, and the intersection point between the connectivity function and the $X$-axis is 3-4 $\mu \mathrm{m}$, which indicate the macro-pores have good connectivity. During the single-channel flow, the pressure decreases along the direction of $\mathrm{CH}_{4}$ flow, and the flow velocity of $\mathrm{CH}_{4}$ decreases from the pore center to the wall. Under the dual-channel and the multi-channel flows, the pressure also decreases along the $\mathrm{CH}_{4}$ flow direction, while the velocity increases. The mean flow pressure gradually decreases with the increase of the distance from the inlet slice. The change of mean flow pressure is relatively stable in the direction horizontal to the bedding plane, while it is relatively large in the direction perpendicular to the bedding plane. The mean flow velocity in the direction horizontal to the bedding plane ( $Y$-axis) is the largest, followed by that in the direction horizontal to the bedding plane ( $X$-axis), and the mean flow velocity in the direction perpendicular to the bedding plane is the smallest.
\end{abstract}

Keywords X-ray $\mu$-CT $\cdot$ Representative elementary volume $\cdot$ Pore network model $\cdot$ Geometric and topological structures · Flow simulation $\cdot$ COMSOL

Edited by Jie Hao

Hui-Huang Fang and Shu-Xun Sang have contributed equally to this work.

Shu-Xun Sang

shxsang@cumt.edu.cn

1 Key Laboratory of Coalbed Methane Resources and Reservoir Formation Process, Ministry of Education, China University of Mining and Technology, Xuzhou 221008, Jiangsu, China

2 School of Resources and Geosciences, China University of Mining and Technology, Xuzhou 221116, Jiangsu, China

3 Low Carbon Energy Institute, China University of Mining and Technology, Xuzhou 221008, Jiangsu, China

4 The Key Laboratory of Coal-Based $\mathrm{CO}_{2}$ Capture and Geological Storage of Jiangsu Province, China University of Mining and Technology, Xuzhou 221008, Jiangsu, China

\section{Introduction}

The coal reservoir is a complex porous medium, which contains matrixes, pores, and minerals (Ni et al. 2017; Li et al. 2019; Liu et al. 2019). The pore structure directly affects the physical property of the coal reservoir (Fu et al. 2017; Su et al. 2019) and further affects the $\mathrm{CH}_{4}$ flow (Naveen et al. 2018; Zhou et al. 2018; Liu et al. 2019). Among the multi-scale pores developed in coal reservoir, most of the macro-pores are connected with nanometer-scale pores and millimeter-scale fractures (Ni et al. 2017), which play important roles in the $\mathrm{CH}_{4}$ flow. The analysis of the 3D spatial structure of the macro-pores and the simulation of $\mathrm{CH}_{4}$ flow with the interconnected pores as the carrier will lay foundations for the study of $\mathrm{CH}_{4}$ flow on the microscopic scales.

In the study of pore structure, traditional methods such as the mercury intrusion porosimetry and the low temperature liquid nitrogen adsorption analysis (Guo et al. 2019; Wang et al. 2018) often destroy the original pore structure during the sample preparation process, so the real 3D pore structures cannot to be characterized. Compared with the 
traditional methods, the focused ion beam scanning electron microscopy (FIB-SEM) and the X-ray computed tomography (i.e., Nano-CT and $\mu$-CT) are new methods to study the pore structure (Yao et al. 2009a; Ma et al. 2014; Shaina et al. 2016; Xiong et al. 2016; Wu et al. 2019a). The FIB-SEM and Nano-CT can only characterize the nanopore structure, and their application and promotion are further limited by the high resolution, long experimental period and strict requirements of sample preparation (Ni et al. 2017). Due to the limited sample size observed, the analysis of the pore structure of coal reservoir with strong heterogeneity is not very representative ( $\mathrm{Ni}$ et al. 2017).

Compared with the FIB-SEM, the X-ray micro-focus computed tomography ( $\mu-\mathrm{CT})$ is a non-destructive scanning technology (Sleutel et al. 2008; Hamamoto et al. 2016), which can not only identify the pores without destroying the original structure, but also solve the contradiction between sample size and scanning resolution (Ni et al. 2017). Based on the X-ray $\mu$-CT, the evolution of coal structure, permeability and heterogeneity (Wolf et al. 2008; Heriawan and Koike 2015), the analysis of coal damage (Viljoen et al. 2015) and the spatial distribution of pores, fractures and minerals (Yao et al. 2009a, b) have been extensively studied. The X-ray $\mu$-CT technology can also be combined with the specific algorithms and the visualization technology to achieve the 3D visualization of coal structure (Yao et al. 2009a, b; Ni et al. 2017). The application of the X-ray $\mu$-CT technology is shown to be effective to study the $3 \mathrm{D}$ pore structure (Sun et al. 2016; Ni et al. 2017).

The visualization analysis of the gas flow with the interconnected pores as the carrier and the discussion of the pressure field and velocity field are of important engineering value for the development of low-permeability reservoirs (Zhou et al. 2016; Ni et al. 2017). Based on the 2D CT slices of the sandstone, Ju et al. (2014) have simulated the gas flow with the interconnected pores in sandstone as the carrier through using the Lattice Boltzmann method, but this method will take a long time and consume a lot of manpower (Li et al. 2017; Yang et al. 2018). With the development of the 3D visualization technology and the multi-field coupling finite element method, Bird et al. (2014) have used the AVIZO software and the COMSOL software to simulate the gas flow with the interconnected pores in carbonate as the carrier. At present, the visualization technology of gas flow at micro-scale is mainly applied to sandstone and carbonate reservoirs ( $\mathrm{Li}$ et al. 2017; Yang et al. 2018). Moreover, the simulation and visualization of the gas flow within the pore scale in coal reservoir are less, especially the $\mathrm{CH}_{4}$ flow. Therefore, it is necessary to explore new ways to simulate and visualize the $\mathrm{CH}_{4}$ flow. Recent studies have shown that the Pore Network Model extracted from the 2D CT slices is composed of the pores, throats and their coordination number (Youssef et al. 2007; Zhao et al. 2018; Wu et al. 2019b), which not only can characterize the complexity of the pore space, but also can be used as the carrier for the $\mathrm{CH}_{4}$ flow simulation on the macro-pore scale (Ni et al. 2017; Blunt 2001; Wu et al. 2019b).

The objective of this study is to realize the docking technology of the programming software and the simulation software through using the STL files and then to realize the analysis of velocity field and pressure field of $\mathrm{CH}_{4}$ flow under various conditions. In this study, the coal sample collected from the southern Qinshui basin in China was firstly scanned by the X-ray $\mu$-CT to obtain the $2 \mathrm{D}$ CT slices. Secondly, the original 2D CT slices were reconstructed and divided to obtain the equivalent pore network model. Then, a mathematical model of $\mathrm{CH}_{4}$ flow simulation with macropores as the carrier was established. Finally, the simulation and its visualization of $\mathrm{CH}_{4}$ flow were realized. The innovations of this study are as follows: (1) a numerical model for coal is built and its equivalent pore network model is extracted based on the X-ray $\mu$-CT data. (2) The distribution of the pressure field and velocity field in signal-, dual-, and multi-channel flows along different directions are revealed. The analysis of the 3D spatial structure and flow simulation of the macro-pores based on the perfect docking of the X-ray $\mu$-CT technology, the image processing technology and the COMSOL can provide new approaches for exploring the $\mathrm{CH}_{4}$ flow in the macro-pore scale.

\section{Experiment and methodology}

\subsection{Sample}

One anthracite coal from the Bofang Mine (BF) in the Jincheng area was collected from the No.3 coal seam of the Shanxi formation in the southern Qinshui basin of China (Fig. 1; Liu et al. 2017; Fang et al. 2017). The collection, retention, and preparation of the coal sample were conducted in line with the relevant Chinese and international standards, such as the GB/T 19222-2003, the GB/T 16773-2008, and the ISO 7404-2:1985 (Liu et al. 2017; Fang et al. 2019). Sample was sealed with absorbent paper to avoid oxidation. The key properties of the sample are shown in Table 1.

\subsection{X-ray $\mu$-CT scanning}

In this study, the X-ray micro-focus CT scanner (i.e., Xradia 510 Versa, the Carl Zeiss Foundation Group) was used for sample scanning, which is a digital core analysis system with resolution up to $0.5 \mu \mathrm{m}$. The experimental coal sample was cylindrical in shape of $\Phi 2.0 \times 2.0 \mathrm{~mm}$, which is placed in the center of the CT system workbench. The energy of the X-ray is $180 \mathrm{kV} / 15 \mathrm{~W}$, the scanning speed is $175 \mathrm{~mm} / \mathrm{s}$, and the image resolution is $0.5 \mu \mathrm{m}$. It is 
necessary to dry the sample before scanning. In this study, the coal sample can be cut into 1013 vertical slices with each thickness of $0.5 \mu \mathrm{m}$. The 1013 slices with $988 \times 988$ pixels can be obtained. Based on the scanning analysis of the tested sample, some typical 2D CT slices can be seen in Fig. 2, and the gray, black, and white represent

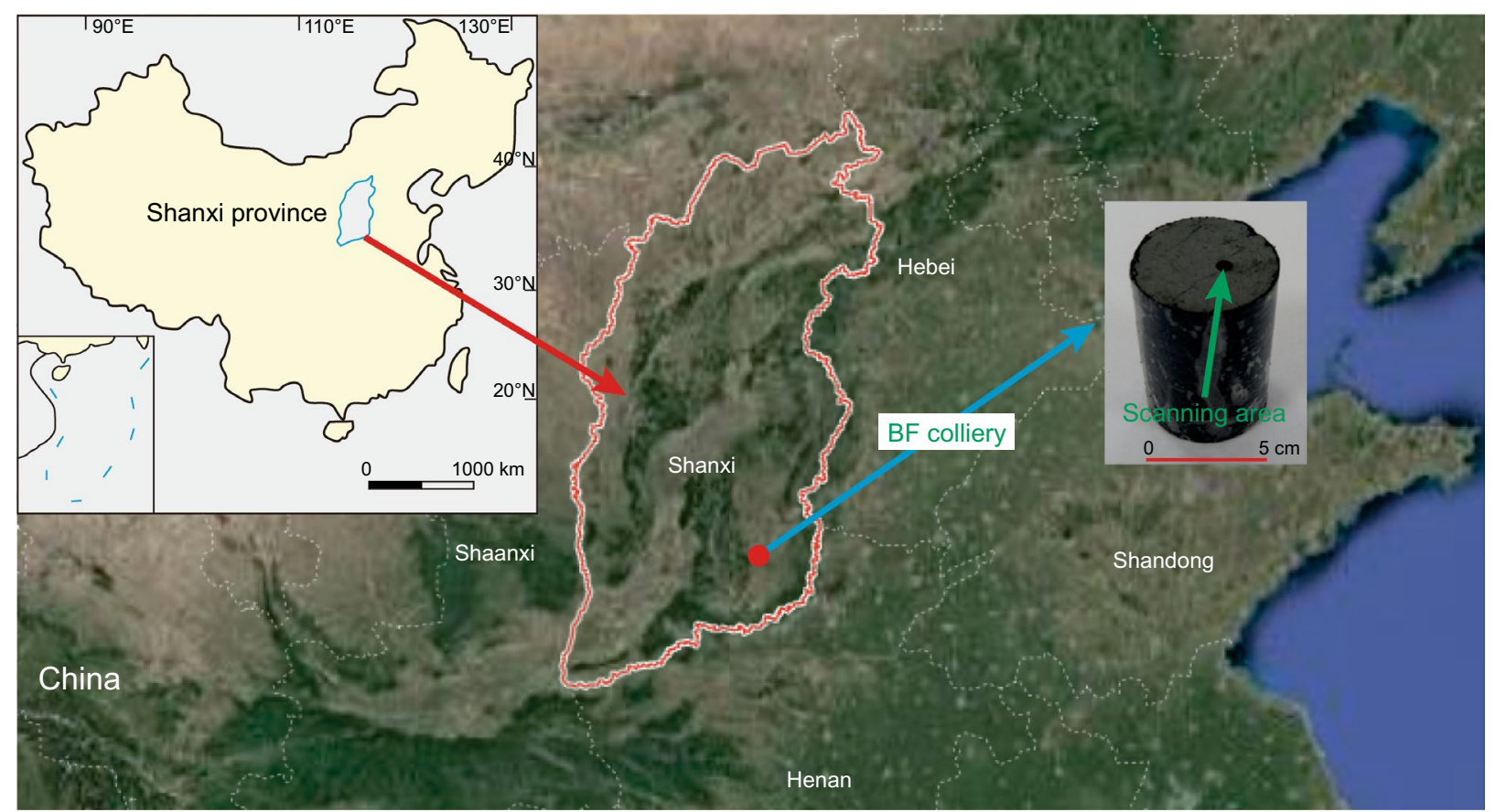

Fig. 1 Sampling point distribution of the BF sample

Table 1 Key properties of coal sample used in this study

\begin{tabular}{|c|c|c|c|c|c|c|c|c|c|}
\hline \multirow[t]{2}{*}{ Sampling location } & \multirow[t]{2}{*}{$R_{\mathrm{o}, \max }, \%$} & \multicolumn{4}{|c|}{ Proximate analysis, wt $\%$} & \multicolumn{4}{|c|}{ Ultimate analysis, wt $\%$} \\
\hline & & $M_{\text {ad }}$ & $A_{\text {ad }}$ & $V_{\text {daf }}$ & $F C_{\text {ad }}$ & $O_{\text {daf }}$ & $C_{\text {daf }}$ & $H_{\text {daf }}$ & $N_{\text {daf }}$ \\
\hline $\mathrm{BF}$ & 2.83 & 2.05 & 9.40 & 9.86 & 81.67 & 2.42 & 91.82 & 3.85 & 1.06 \\
\hline
\end{tabular}

wt $\%$, weight percent; $R_{\mathrm{o}, \max }$, average maximum vitrinite reflectance; $M_{\mathrm{ad}}$, moisture; $A_{\mathrm{ad}}$, ash yield; $V_{\mathrm{daf}}$, volatile matter; $F C_{\mathrm{ad}}$, fixed carbon content; $O_{\mathrm{daf}}$, content of oxygen; $C_{\mathrm{daf}}$, content of carbon; $H_{\mathrm{daf}}$, content of hydrogen; $N_{\mathrm{daf}}$, content of nitrogen; "ad," air-drying base; "daf," dry ashfree basis
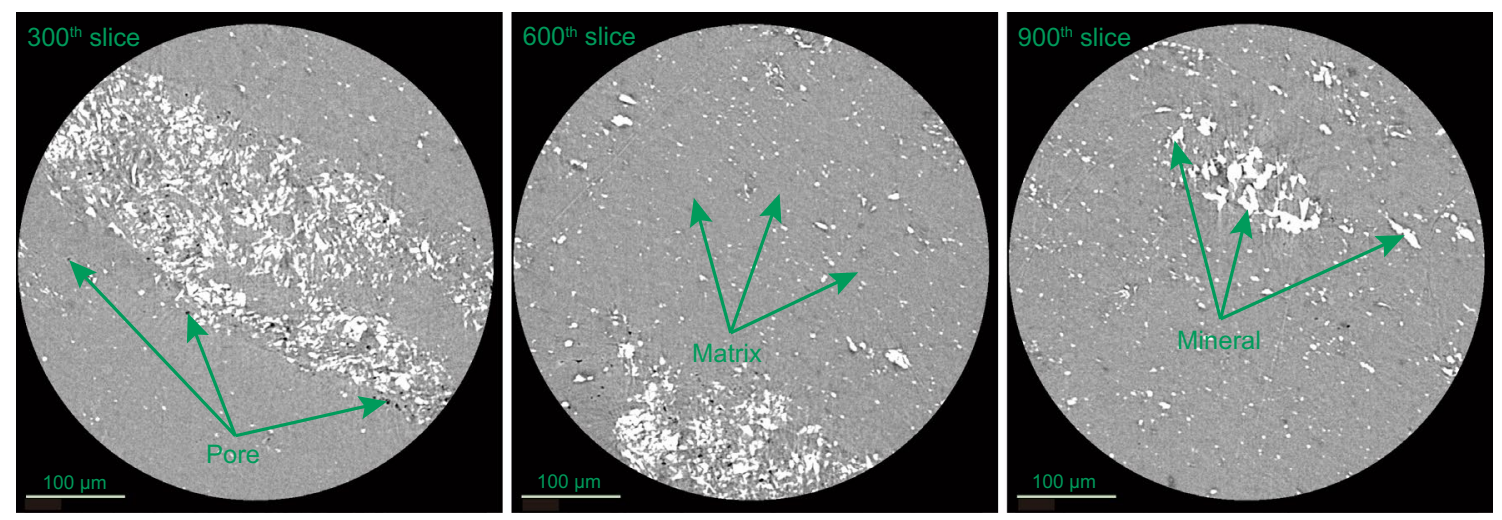

Fig. 2 Typical 2D CT slices of BF coal sample (the gray, black, and white represent the matrixes, pores, and minerals, respectively, inside the circle) 
the matrixes, pores, and minerals, respectively, inside the circle (Fig. 2).

\subsection{Image processing}

The original 2D CT slices of the BF sample should be reconstructed and segmented to obtain the equivalent Pore Network model, which includes the pre-processing of 2D CT slices, the image segmentation, the selection of the representative elementary volume and the extraction of the equivalent pore network model.

\subsubsection{Pre-processing of 2D CT slices}

It is generally known that the higher the image processing accuracy is, the better the 3D reconstruction effect of the pore structure will be (Zhou et al. 2016). The original 2D CT slices obtained based on the X-ray $\mu$-CT scanning are more or less affected by noise, so there are scatter dots noise in the CT slices (Fig. 3a), which will have an adverse impact on image segmentation in the following operation; therefore, the original 2D CT slices need to be de-noised. The median filter can not only protect the integrity of the pores but also smooth the transition between the pores and the matrixes (Li and Zhang 2019), which can de-noise the original 2D CT slices. In this study, the original 2D CT slices are processed by the 3D Median filter with 18 neighborhoods, and the results are shown in Fig. 3b.

\subsubsection{Image segmentation}

The conversion from the 2D CT slices into the segmented images is the primary purpose of threshold segmentation, which can separate the pore and matrix from the coal, and further separate the organic matter and mineral from the matrix. The porosity $(\varphi)$ of the scanned sample can be obtained through the laboratory experiment, and the segmentation threshold obtained based on the porosity of the digital core can be used to segment the image (Fang et al. 2018). First, a rough threshold range can be obtained by using the porosity method. Then, multiple pore extraction should be carried out to compare the distribution of pores in the original 2D CT Slices. Finally, the threshold range should be further adjusted to get the optimal threshold. The equation is as follows:

$f(K)=\operatorname{MIN}\left\{f(K)=\left|\varphi-\frac{\sum_{i=I_{\min }}^{K} p(i)}{\sum_{i=I_{\min }}^{I_{\max }} p(i)}\right|\right\}$

where $K$ is the segmentation threshold; $\varphi$ is the porosity; $I_{\max }$ and $I_{\min }$ are the maximum and minimum grayscale values of the image; and $P(i)$ is the voxel number with grayscale value of $i$.

Voxels with grayscale values below the segmentation threshold represent pores, while those with grayscale values greater than the segmentation threshold represent matrixes and minerals. The 3D reconstruction of coal sample, and the pores, matrixes and minerals can be separated from the reconstructed coal based on the segmentation threshold (Fig. 4).

\subsubsection{Representative elementary volume}

The representative elementary volume (REV) is the smallest unit, which can effectively characterize the macroscopic physical property of coal (Vik et al. 2013; Yuan et al. 2015). Selecting an appropriate REV is the key to analyzing the 3D spatial structure of pore, which can effectively reduce
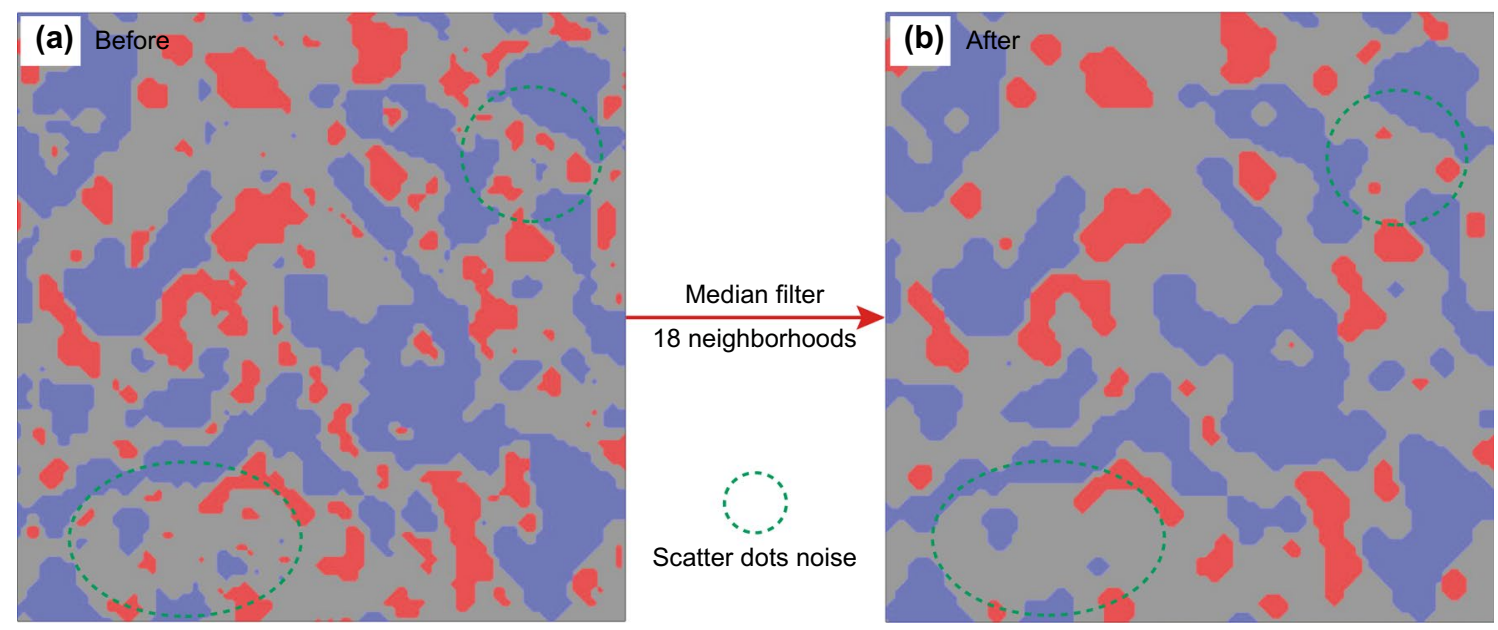

Fig. 3 Comparison of images before and after filtration. a Image before filtration; $\mathbf{b}$ image after filtration 


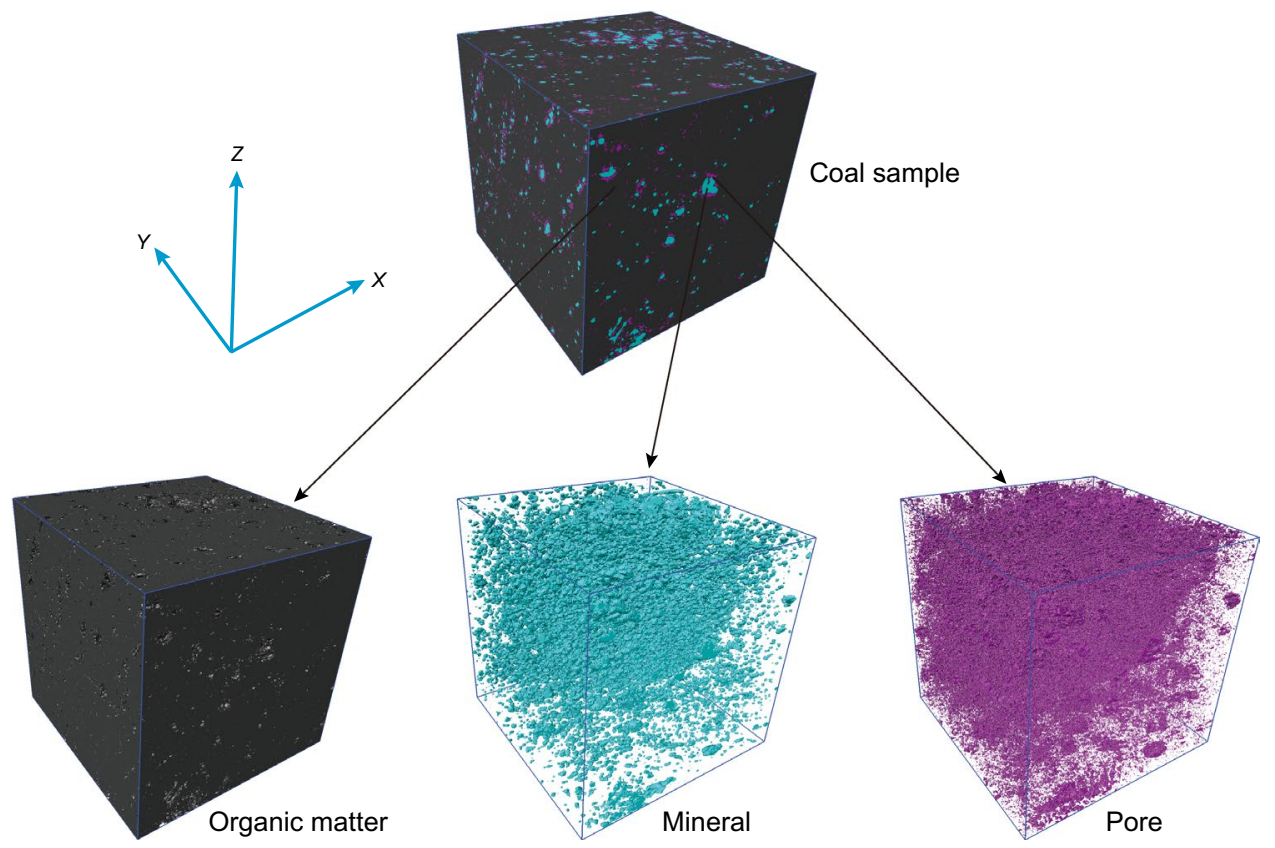

Fig. 4 3D reconstruction of coal sample

the memory capacity and speed up the calculation (Harpreet 2017). After many calculations, the results demonstrate that the porosity of coal has nothing to do with the sample size when the sample size is over $500 \times 500 \times 500$ voxels (Fig. 5). Therefore, the $500 \times 500 \times 500$ voxels are chosen to characterize the sample size, and the actual sample size is $250 \times 250 \times 250 \mu^{3}$.

\subsubsection{Equivalent pore network model}

The equivalent pore network model is the carrier of $\mathrm{CH}_{4}$ flow. Understanding the number, radius and length of throats, as well as the relative position and connectivity of pores and throats are the prerequisite for analyzing the geometrical and topological structures of the pore network model, as well as the basis for further simulating and visualizing the $\mathrm{CH}_{4}$ flow.

The Maximum Ball method can be used to establish the pore network model, and the specific principles are as follows (Silin and Patzek 2006; Lei et al. 2018): the Maximum Ball method takes any point in pore space as the reference point (red part in Fig. 6) and constantly looks for the maximum inscribed sphere with this point as the circle center and tangent to the skeleton boundary (red circle in Fig. 6). After all the inscribed spheres are found, the spheres contained in other inscribed spheres will be removed, and the remaining spheres will constitute the largest ball set. The clustering algorithm is introduced to classify and merge the maximum sphere and identify pores and throats. Pores can be represented by the larger spheres
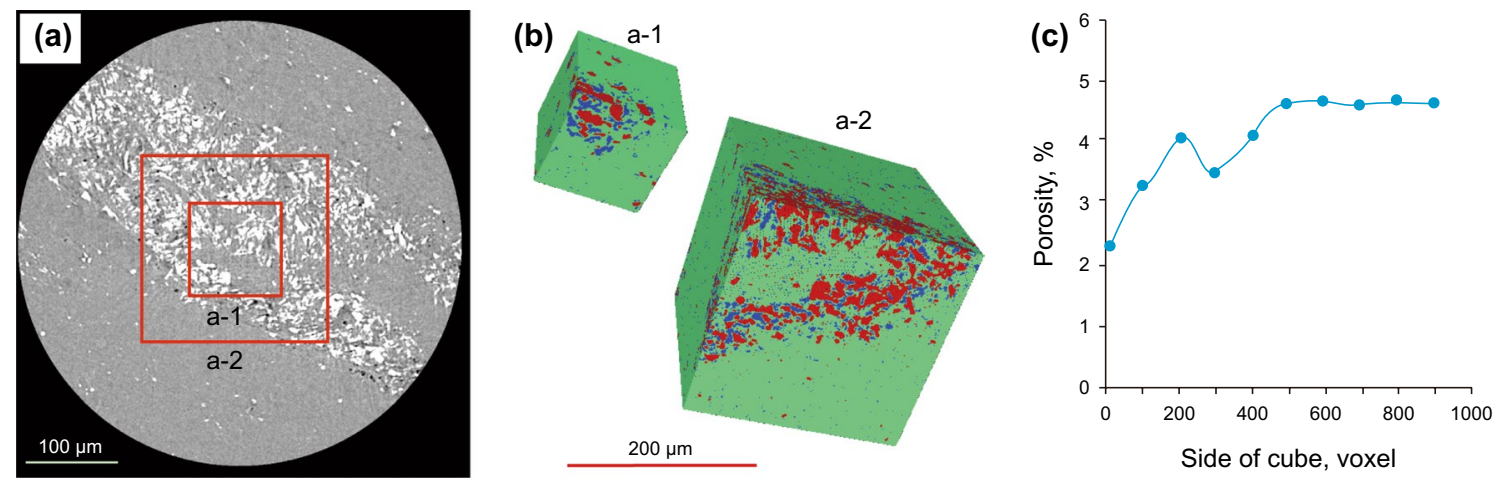

Fig. 5 Schematic diagram of REV analysis. a Original 2D CT slice; b REV; $\mathbf{c}$ relationship between the porosity and the sample size 


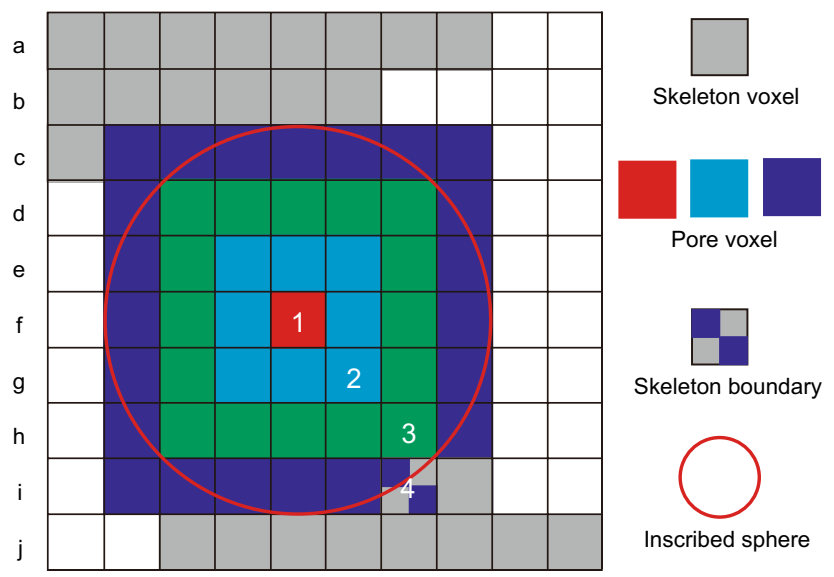

Fig. 6 Sketch of the maximum ball method. Modified from Lei et al. (2018)

and throats between pores can be represented by a series of smaller spheres (Fig. 6). Figure 7 denotes the pore network model of the BF sample, and the cylinder and sphere represent the throats and the pores, respectively.

\subsection{Flow simulation}

In order to simulate and visualize the $\mathrm{CH}_{4}$ flow after extracting the Pore Network model, the following steps such as the pre-processing of pore grid, the controlling equations and the basic setting of the boundary conditions need to be established. Although a computer with 24 GB of the random-access memory has been used, the 3D mesh is often interrupted by a memory overflow in COMSOL when the sample size exceeds $60 \times 60 \times 60$ voxels. Therefore, the sample sizes have to be reduced to $60 \times 60 \times 60$ voxels (i.e., $30 \times 30 \times 30 \mu^{3}$ ) for $\mathrm{CH}_{4}$ flow simulation as derived from REV interception in this study (Fig. 8).

\subsubsection{Pre-processing of pore grid}

The interconnected pores and throats are the major channels for $\mathrm{CH}_{4}$ flow. Therefore, it is necessary to extract the interconnected pores and throats in the pore network model. The interconnected pores and throats which can represent the real connected environment of the BF sample can be extracted based on the corresponding programming in the MATLAB software (Fig. 8a), and the output STL file can be imported into the COMSOL (www.comso

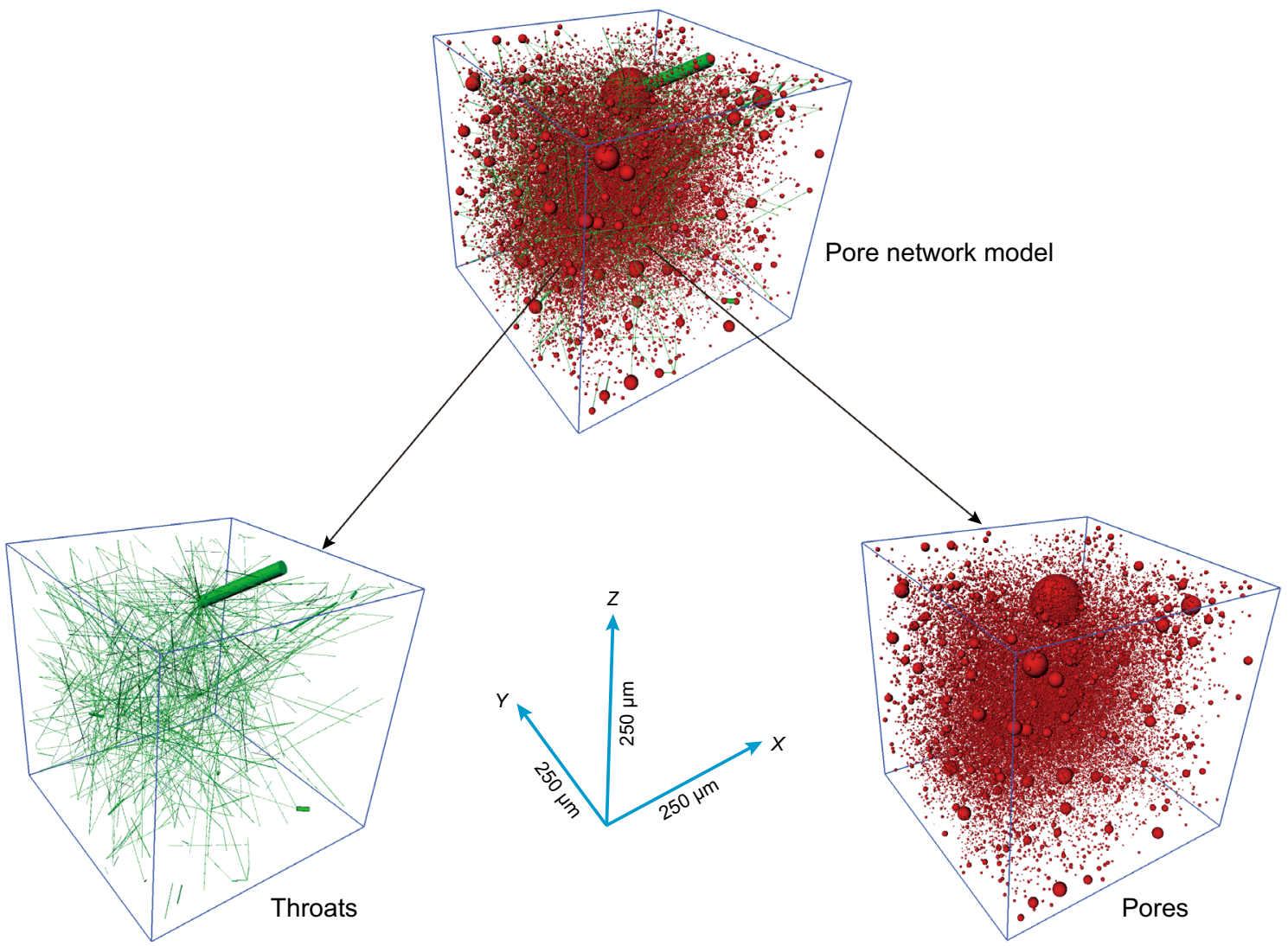

Fig. 7 Extraction of pores and throats 

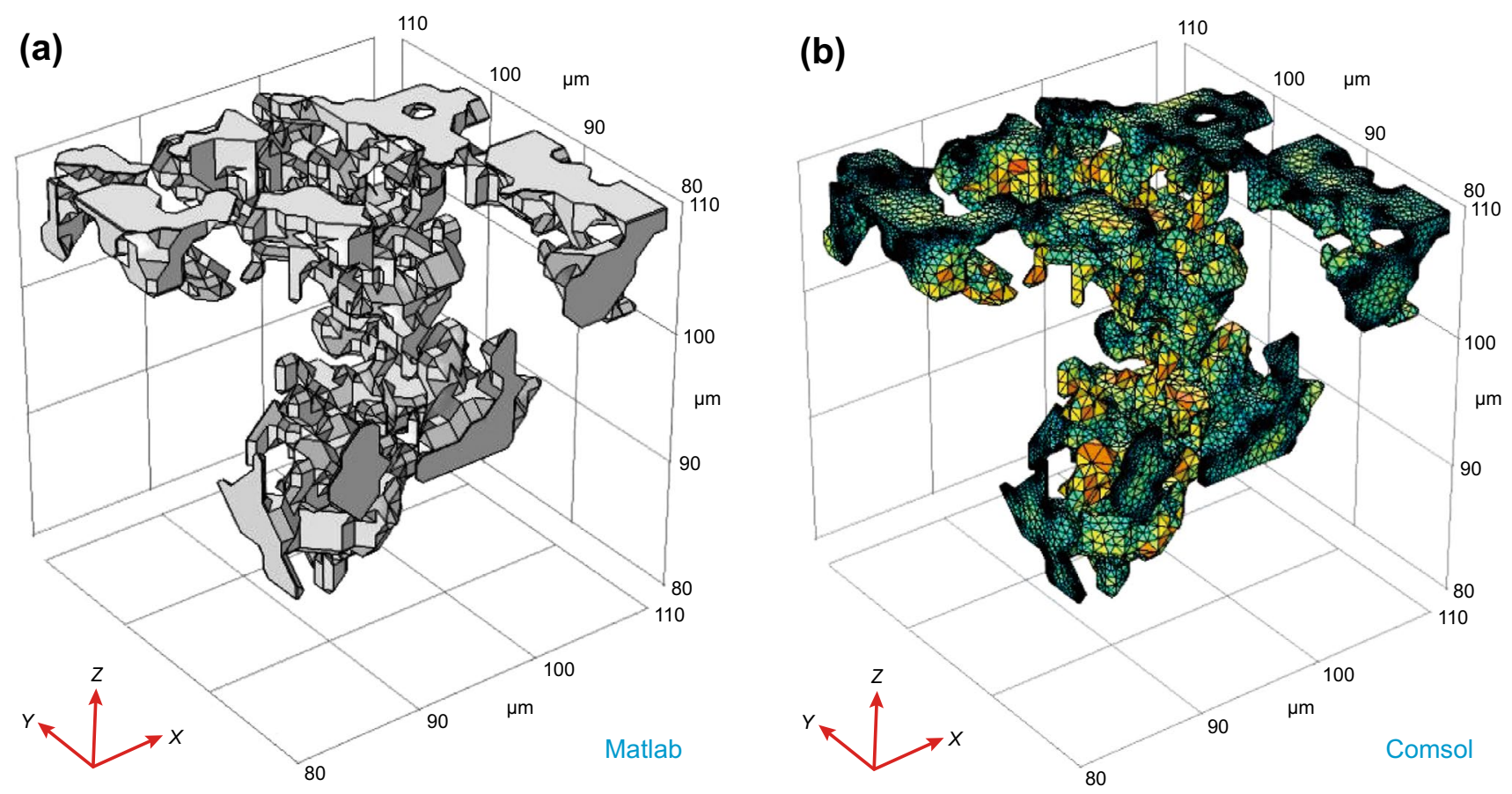

Fig. 8 Digital coal model $(60 \times 60 \times 60$ voxels $)$. a Interconnected pore network model in MATLAB software, and b grid generation in COMSOL software

1.com) to simulate the $\mathrm{CH}_{4}$ flow. Due to the complex pore structure, the errors or warnings often occur when the Pore Network model is meshed in the COMSOL. Therefore, the Pore Network model should be manually debugged in the COMSOL, which includes the restoration of the notches and sharp corners, and the elimination of the intersect, aperture, small hole, chamfer, interface, and coincident edge (Zhou et al. 2016; Ni et al. 2017). Through continuous debugging, the flawless tetrahedral mesh for numerical simulation can be generated in COMSOL (Fig. 8b).

\subsubsection{Controlling equations of flow simulation}

In this study, it is assumed that the fluid is incompressible and the flow is laminar in the pore network model. The Navier-Stokes model and the continuity equation can be applied to the flow simulation, which are as follows:

$\rho(\boldsymbol{v} \cdot \nabla) \boldsymbol{v}=\nabla \cdot[-P \cdot \mathbf{I}+\mathbf{K}]+\mathbf{F}$

$\rho \nabla \cdot(v)=0$

$\mathbf{K}=\mu\left(\nabla v+(\nabla v)^{\mathrm{T}}\right)$

where $\rho, v, P$, and $\mu$ denote the density, velocity, pressure, and viscosity of fluid, respectively.
The constant-pressure boundary is adopted for the inlet boundary (Eqs. 5, 6) and exit boundary (Eqs. 6, 7) in COMSOL software, which are as follows:

$P=P_{\text {inlet }}$

$\mathbf{n} \cdot \mu \nabla^{2} v=0$

$P=P_{\text {exit }}$

The boundary conditions of the remaining boundaries are shown below:

$\mathbf{n} \cdot v=0$

$t \cdot \mu\left(-\nabla P+\mu \nabla^{2} v\right) \mathbf{n}=0$

\subsubsection{Basic settings of flow simulation}

The parameters of the fluid (i.e., density and viscosity) were determined according to the $\mathrm{CH}_{4}$ properties under standard conditions during the simulation processes, but the influence of temperature and pressure on viscosity and density was not taken into account in this study. The model boundary conditions are loaded as shown in Fig. 9. There are three directions in the model, and two relative boundaries are selected as the 

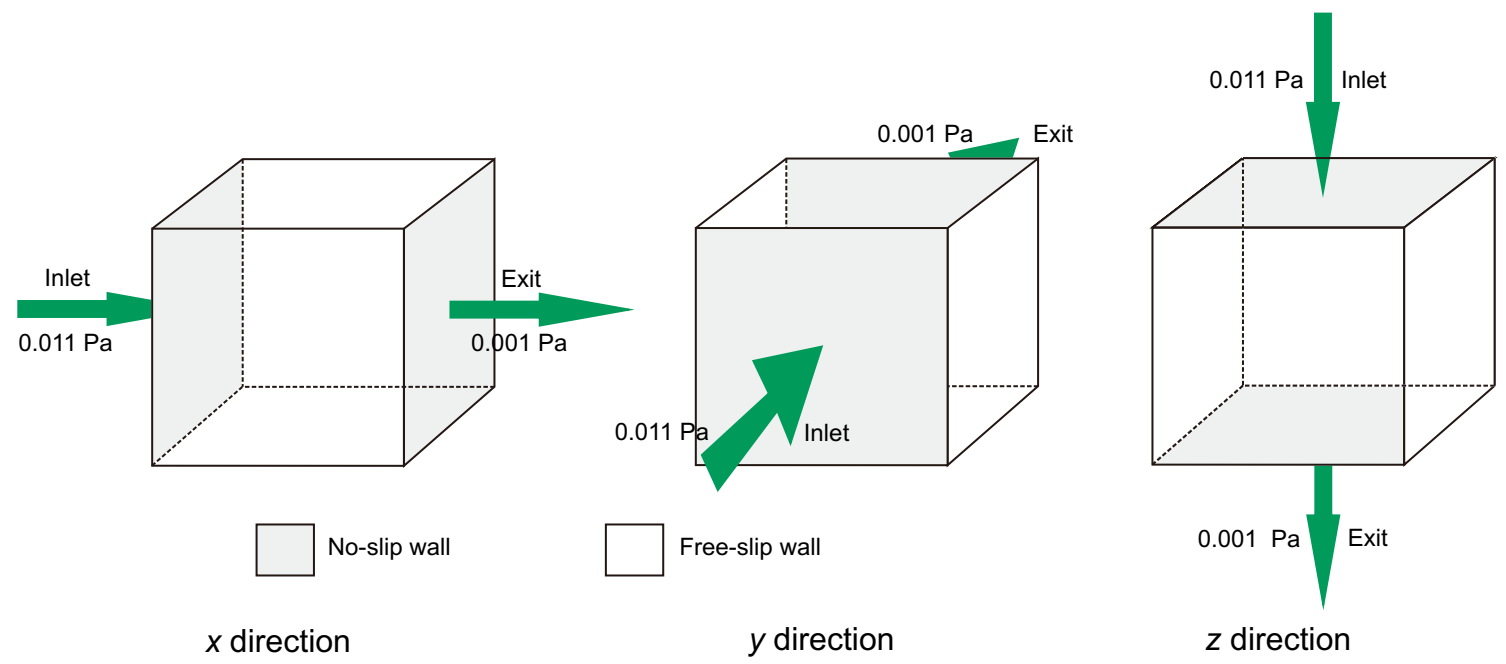

Fig. 9 Diagram of loading condition in boundaries of three directions. Notes: $X$ and $Y$ direction means the direction horizontal to the bedding plane, and $Z$ direction means the direction perpendicular to the bedding plane

inlet and exit of pressure. The inlet and exit pressures were set as $0.011 \mathrm{~Pa}$ and $0.001 \mathrm{~Pa}$, respectively, according to the pressure gradient of the formation in the study area (Fang et al. 2019). The inlet and exit boundaries are defined as no-slip wall, and the other four boundaries are defined as free-slip wall.

\section{Results and discussion}

According to the pore diameter, the pores can be divided into micro-pores $(<10 \mathrm{~nm})$, transition pores $\left(10-10^{2} \mathrm{~nm}\right)$, mesopores $\left(10^{2}-10^{3} \mathrm{~nm}\right)$, and macro-pores $\left(>10^{3} \mathrm{~nm}\right.$; Hodot 1966 ; Zhao et al. 2019). The pores extracted from the BF sample in this study are macro-pores based on the pore structure classification system mentioned above. In order to better understand the geometrical and topological structures of the pore network model, the following parameters are defined (Lindquist et al. 2000; Sok et al. 2002; Herring et al. 2013; Zhao et al. 2018; Liu et al. 2019): (1) pore radius is the radius of the equivalent sphere with the same volume; (2) throat radius and length are the radius and length of the channel connecting two interconnected pores; (3) coordination number is the connective number between one pore and other pores; (4) Euler's characteristic is also known as the connectivity function, which can be obtained by calculating the relative Euler characteristics of the minimum radius of the pores and throats.

\subsection{Structural characteristics of pore network model}

\subsubsection{Geometric structure}

The number of macro-pores gradually decreases with the increase of pore radius (Fig. 10a). When the pore radius is greater than $7 \mu \mathrm{m}$, the pore number is less than 10 in each range of radius (Fig. 10a). When the pore radius is approximately $2 \mu \mathrm{m}$, the pore volume reaches its maximum value (Fig. 10b). The equivalent radius of throats is between 1.03 and $8.9 \mu \mathrm{m}$, and their number decreases with the increase of radius. The number of throats with radius less than $3 \mu \mathrm{m}$ occupies $96.07 \%$ of the total throats (Fig. 10c). The length of throats is between 3.28 and $231.25 \mu \mathrm{m}$, and their number also decreases with the increase of radius (Fig. 10d).

\subsubsection{Topological structure}

The coordination number plays an important role in controlling the $\mathrm{CH}_{4}$ flow (Rabbani et al. 2014; Song et al. 2017). The greater the value is, the better the connectivity of pores will be (Lindquist et al. 2000; Sok et al. 2002; Liu et al. 2019). The coordination number of pores concentrates around three in BF sample (Fig. 11a), which indicates that most of the pores can be interconnected with other three pores, and the flow 

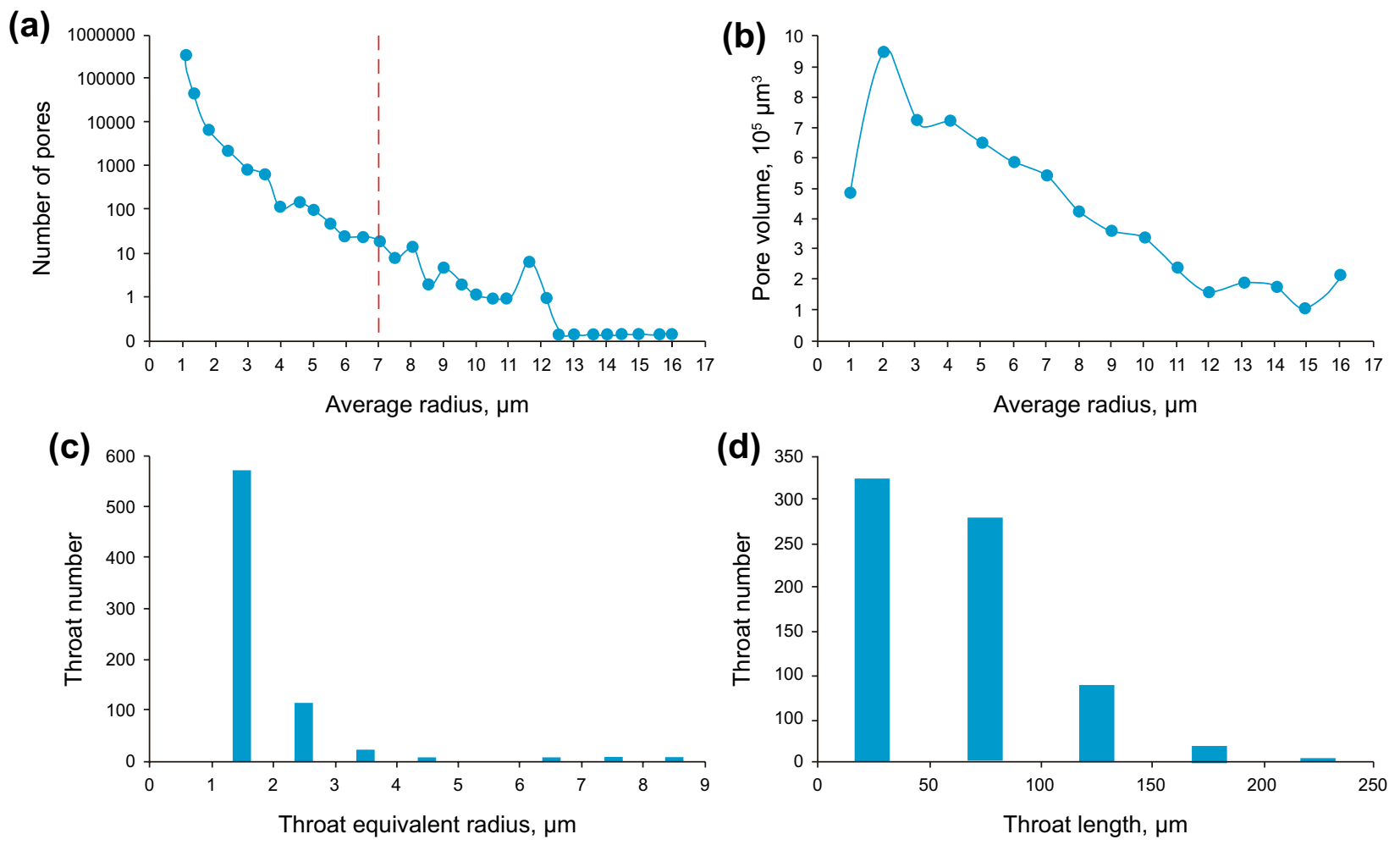

Fig. 10 Geometric structure of pore network model. a Pore size distribution; b pore volume distribution; c throat equivalent radius statistics; d throat length statistics
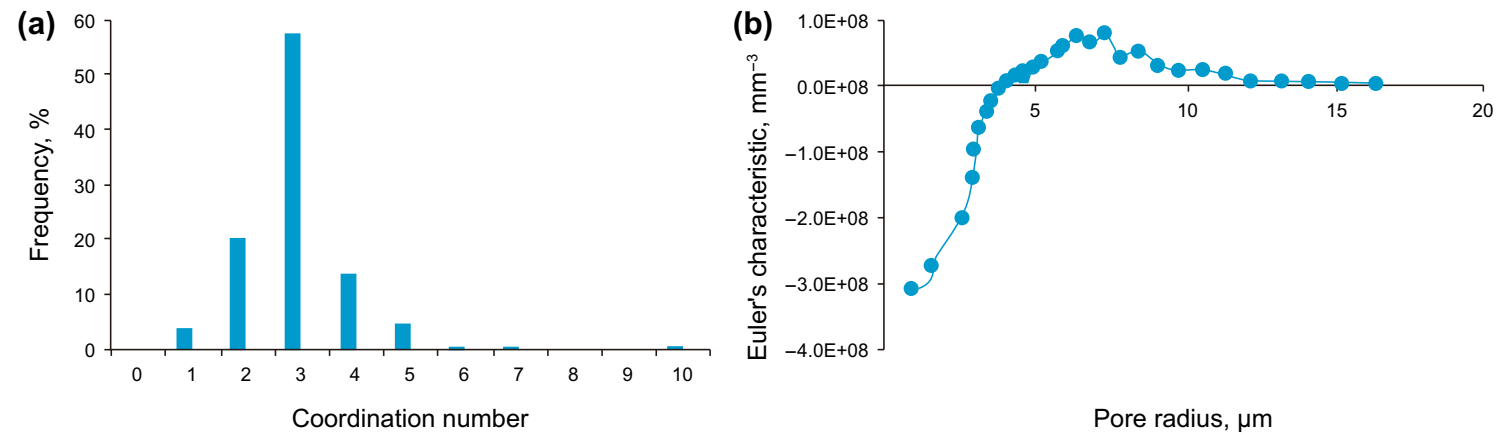

Pore radius, $\mu \mathrm{m}$

Fig. 11 Topological structure of pore network model. a Coordination number; b Euler's characteristic number

path is wide. The closer the intersection point between the connectivity function and the $X$-axis is to zero, the poorer the pore connectivity will be (Silin and Patzek 2006; Vogel and Roth 2001). The intersection point is $3-4 \mu \mathrm{m}$ in BF sample (Fig. 11b), which indicates that macro-pores with the width of 3-4 $\mu \mathrm{m}$ play a major role in the connectivity of pores.

\subsection{Distribution of pressure field and velocity field}

\subsubsection{Single-channel flow characteristic}

The distribution of the pressure field and velocity field on single-channel flow condition along the direction 

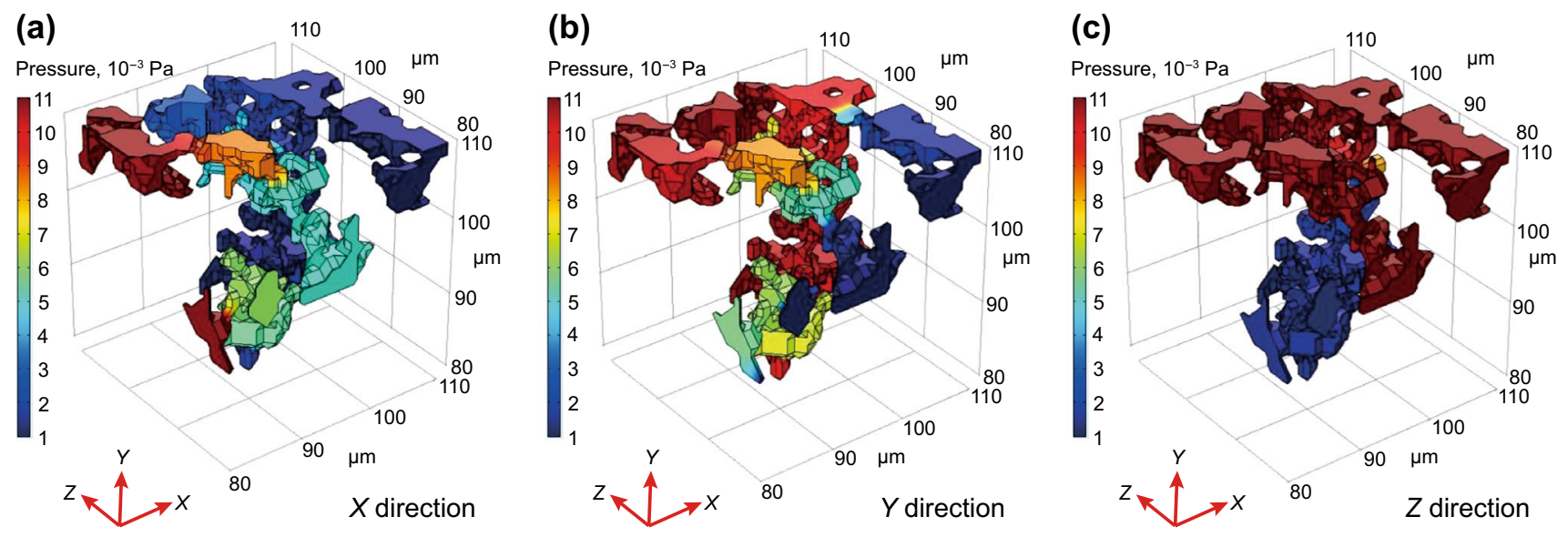

Fig. 12 Distribution of pressure along a single-channel in $X, Y$, and $Z$ directions. Notes: $X$ and $Y$ direction means the direction horizontal to the bedding plane, and $Z$ direction means the direction perpendicular to the bedding plane
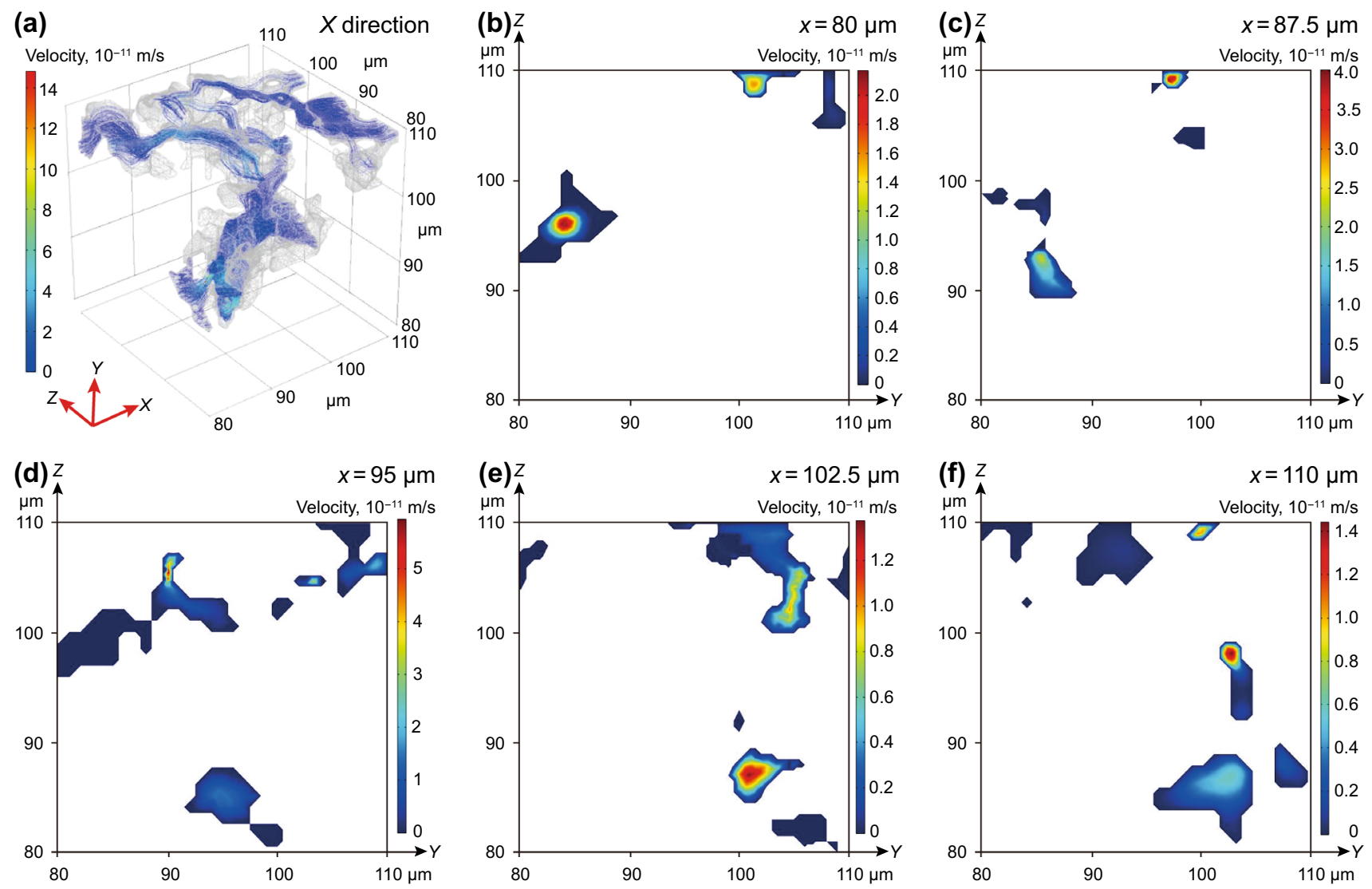

Fig. 13 Distributions of velocity of a 3D view and b-f different slices along a single-channel in $X$ direction. b $x=80 \mu \mathrm{m} ; \mathbf{c} x=87.5 \mu \mathrm{m}$; d $x=95 \mu \mathrm{m} ; \mathbf{e} x=102.5 \mu \mathrm{m} ; \mathbf{f} x=110 \mu \mathrm{m}$. Notes: $X$ direction means the direction horizontal to the bedding plane

perpendicular and horizontal to the bedding plane can be obtained by analyzing the post-processing module in COMSOL software (Figs. 12, 13, 14, 15).

During the single-channel flow, the pressure-dropping $(\Delta P)$ along the direction perpendicular and horizontal to the bedding plane are the same $(0.01 \mathrm{~Pa})$, but the 3D distribution of the pressure in different directions is quite different, and the mean flow pressure along the direction horizontal ( $X$-axis and $Y$-axis) and perpendicular to the bedding plane is $5.64 \times 10^{-3} \mathrm{~Pa}, 7.84 \times 10^{-3} \mathrm{~Pa}$, and $3.08 \times 10^{-3} \mathrm{~Pa}$, 

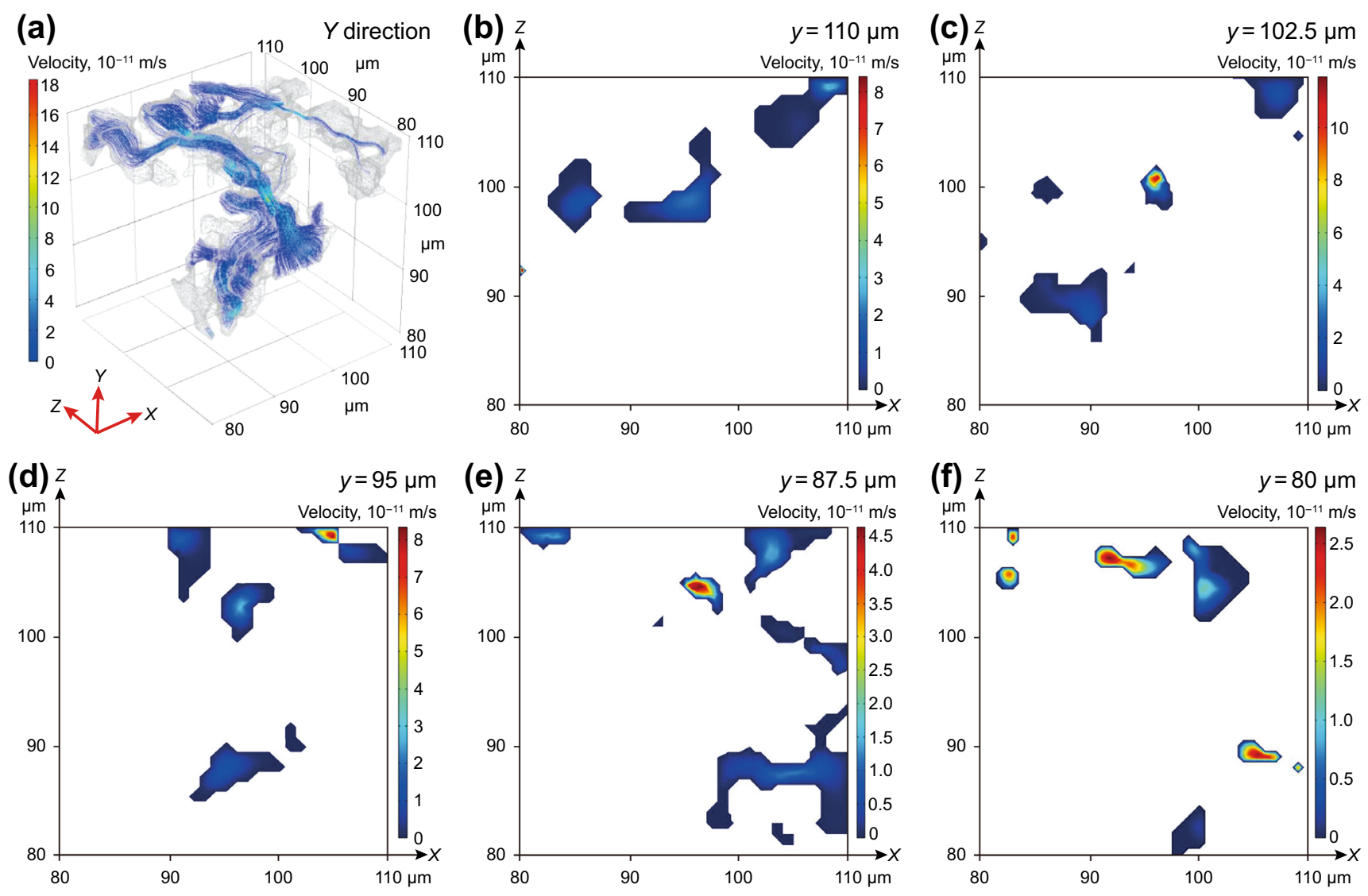

Fig. 14 Distributions of velocity of $\mathbf{a} 3 \mathrm{D}$ view and $\mathbf{b}-\mathbf{f}$ different slices along a single-channel in $Y$ direction. $\mathbf{b} y=110 \mu \mathrm{m} ; \mathbf{c} y=102.5 \mu \mathrm{m} ; \mathbf{d}$ $y=95 \mu \mathrm{m} ; \mathbf{e} y=87.5 \mu \mathrm{m} ; \mathbf{f} y=80 \mu \mathrm{m}$. Notes: $Y$ direction means the direction horizontal to the bedding plane

respectively (Fig. 12). This lies in the difference of radius, shape, and connectivity of pores and throats. Specifically, the pressure decreases gradually along the direction of the $\mathrm{CH}_{4}$ flow, and the maximum pressure appears in the narrow pores near the inlet boundary. The pressure rapidly changes at the narrow pores, which decreases first and then increases (Fig. 12).

The velocity distribution of 3D view and different sections (i.e., $x=80,87.5,95,102.5$ and $110 \mu \mathrm{m} ; y=110$, $102.5,95,87.5$ and $80 \mu \mathrm{m} ; z=110,102.5,95,87.5$ and $80 \mu \mathrm{m}$ ) along the single-channel flow in the direction perpendicular and horizontal to the bedding plane can be seen in Figs. 13, 14 and 15.

Although the pressure dropping in three directions are the same, the velocity distribution in the direction perpendicular and horizontal to the bedding plane are quite different (Figs. 13a, 14, 15a). Some findings are as follows: (1) Although all the pores are interconnected in the largest poreconnected group (Fig. 8), the $\mathrm{CH}_{4}$ flow can only be observed in some pores (Figs. 13, 14, 15). The $\mathrm{CH}_{4}$ firstly flows along the path with large radius, then the short distance from the outlet. (2) As for the $\mathrm{CH}_{4}$ flow in a single pore, the velocity gradually decreases from the center of the pore to the wall, and until it becomes zero (Figs. 13, 14, 15). In terms of the whole pore structure, the maximum velocity appears in the central region where the $\mathrm{CH}_{4}$ flow is fully developed. (3) Although the mean flow velocity on single-channel along the direction horizontal ( $X$-axis and $Y$-axis) and perpendicular to the bedding plane is about $2.97 \times 10^{-12} \mathrm{~m} / \mathrm{s}$, $5.23 \times 10^{-12} \mathrm{~m} / \mathrm{s}$, and $1.97 \times 10^{-12} \mathrm{~m} / \mathrm{s}$, respectively, the flow velocity in different sections are quite different (Figs. 13, 14, 15). (4) In different sections, the maximum velocity appears in the center of the pore channels. Due to the rapid bending of pore channels and the rapid decrease of pore diameter, the velocity of the $\mathrm{CH}_{4}$ flow in the narrow pores is the fastest (Figs. 13, 14, 15).

In order to further analyze the distribution of pressure field and velocity field at different slices (i.e., the distance of slices from the flow inlet slice is $0,7.5,15,22.5$ and $30 \mu \mathrm{m}$, respectively) along a single-channel in the direction horizontal and perpendicular to the bedding plane, the average value of pressure and velocity on different slices is analyzed (Fig. 16). In different directions, the distribution of mean flow pressure from the inlet to the outlet has the same distribution law, and the mean flow pressure gradually decreases with the distance from the flow inlet 
(a)
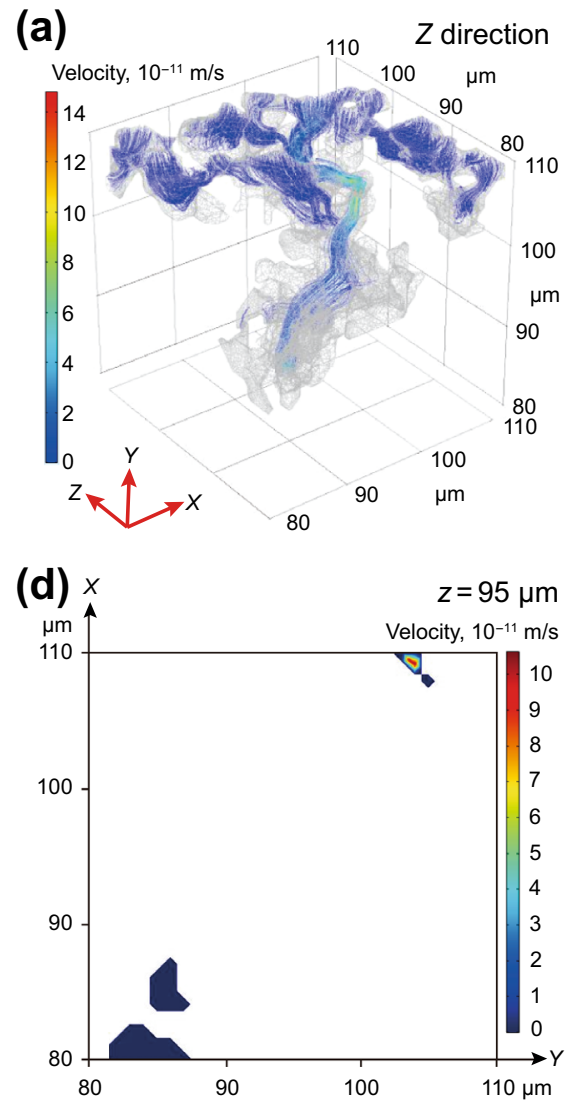
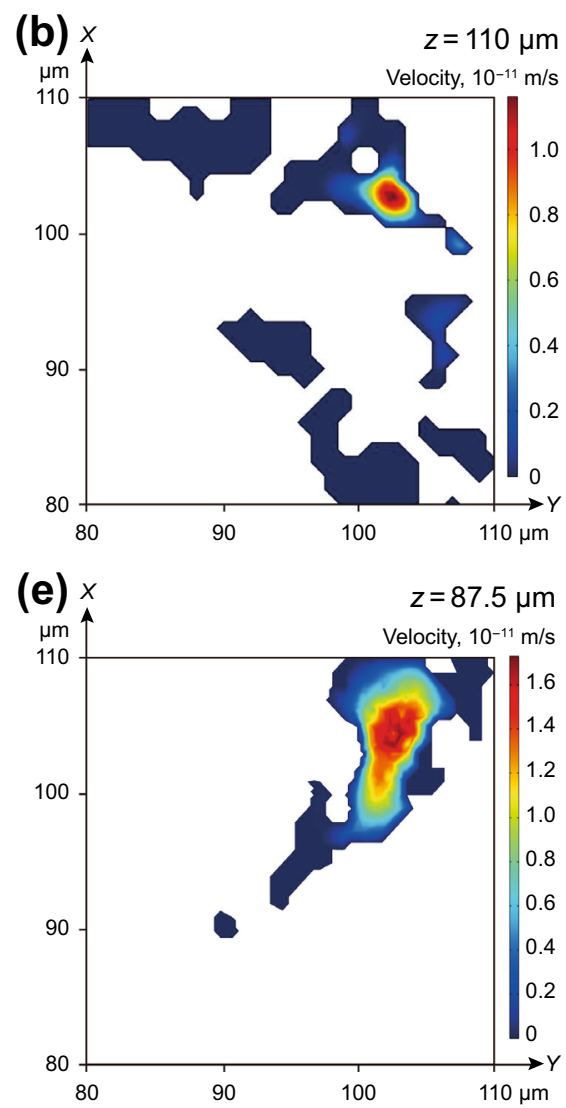
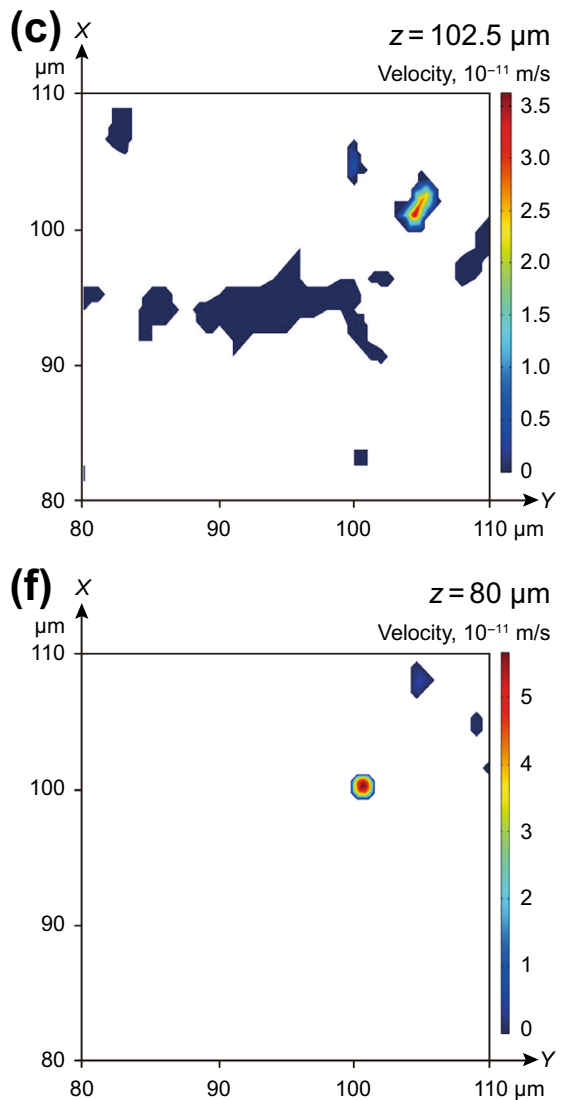

Fig. 15 Distributions of velocity of a 3D view and $\mathbf{b}-\mathbf{f}$ different slices along a single-channel in $Z$ direction. $\mathbf{b} z=110 \mu \mathrm{m} ; \mathbf{c} z=102.5 \mu \mathrm{m} ; \mathbf{d}$ $z=95 \mu \mathrm{m} ; \mathbf{e} z=87.5 \mu \mathrm{m} ; \mathbf{f} z=80 \mu \mathrm{m}$. Notes: $Z$ direction means the direction perpendicular to the bedding plane
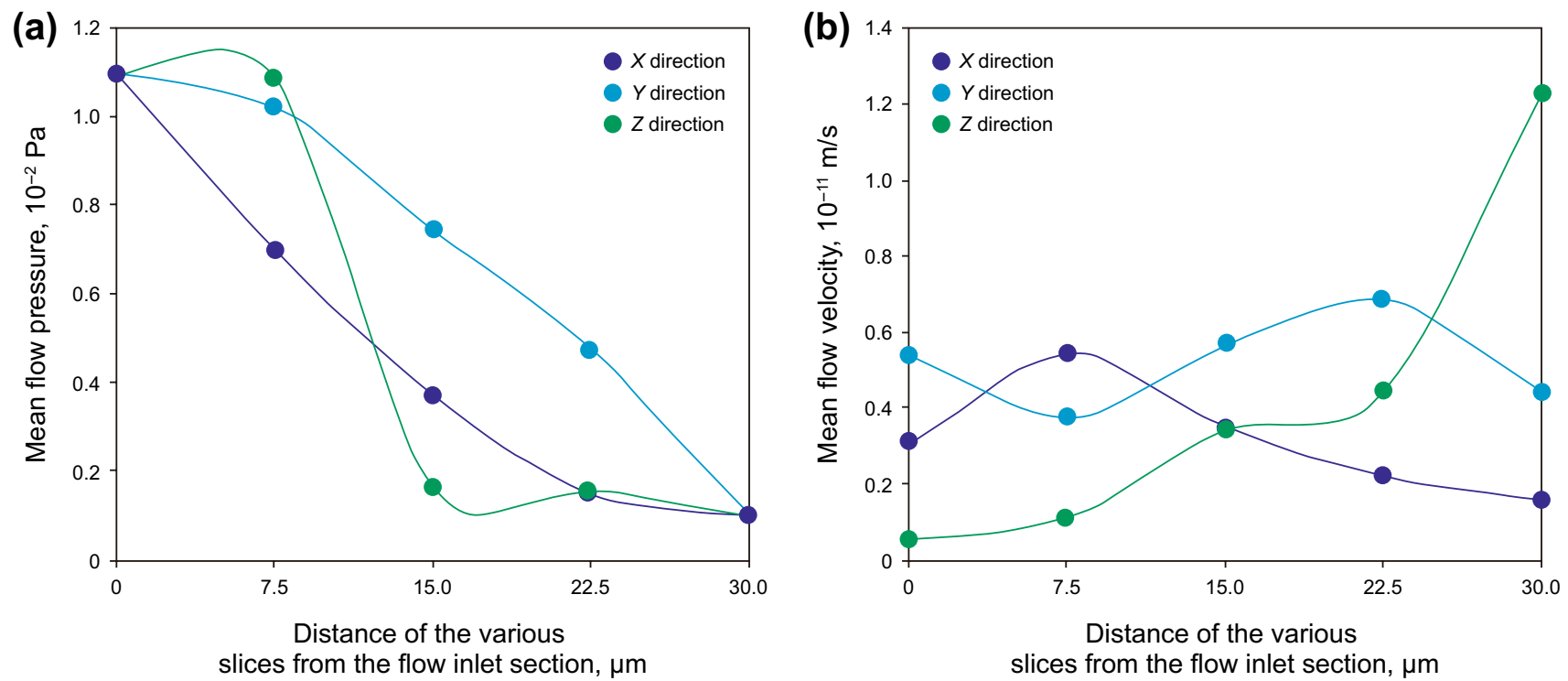

Fig. 16 Distribution of $\mathbf{a}$ mean flow pressure and $\mathbf{b}$ mean flow velocity at different slices along a single-channel in the direction horizontal and perpendicular to the bedding plane. Notes: $X$ and $Y$ direction means the direction horizontal to the bedding plane, and $Z$ direction means the direction perpendicular to the bedding plane 
slice (Fig. 16a). The changes of mean flow pressure in the direction horizontal to the bedding plane are relatively stable, while the changes in the direction perpendicular to the bedding plane are relatively large (Fig. 16a). In the direction horizontal to the bedding plane, the changes of mean flow velocity of various slices are relatively stable with the value of $(0.4-0.6) \times 10^{-11} \mathrm{~m} / \mathrm{s}$ (Fig. 16b). In the direction perpendicular to the bedding plane, there is a significant difference in mean flow velocity of various slices with the value of $(0.05-1.2) \times 10^{-11} \mathrm{~m} / \mathrm{s}$ (Fig. 16b). The mean flow velocity in the direction horizontal ( $Y$-axis) to the bedding plane was the largest, followed by that in the direction horizontal ( $X$-axis) to the bedding plane, and the mean flow velocity in the direction perpendicular to the bedding plane was the smallest (Fig. 16b), which is consistent with the distribution of mean flow pressure in different directions (Fig. 16).

\subsubsection{Dual- and multi-channel flow characteristics}

For the dual-channel and multi-channel flow, the former means the $\mathrm{CH}_{4}$ flows along the $X+Y, X+Z$ and $Y+Z$ directions at the same time, and the latter means the $\mathrm{CH}_{4}$ flows along the $X+Y+Z$ directions simultaneously, so the direction of the dual-channel flow is the $X+Y, X+Z$ and $Y+Z$ directions, and the direction of the multi-channel flow is the $X+Y+Z$ directions (Figs. 17, 18, 19). The distribution of pressure field and velocity field during the dual-channel and multi-channel flow can be seen in Figs. 17, 18 and 19.

The mean flow pressure along the $X+Y, X+Z, Y+Z$ directions in the dual-channel flow, and along the $X+Y+Z$ directions in the multi-channel flow is $4.83 \times 10^{-3} \mathrm{~Pa}$, $6.92 \times 10^{-3} \mathrm{~Pa}, 7.16 \times 10^{-3} \mathrm{~Pa}$, and $5.71 \times 10^{-3} \mathrm{~Pa}$, respectively. Similar to the pressure condition in the single-channel flow along the $X, Y$, and $Z$ directions, the pressure decreases (a)

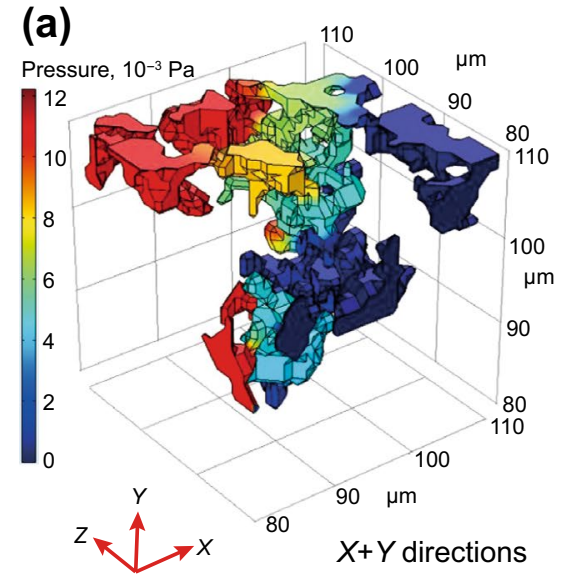

(b)

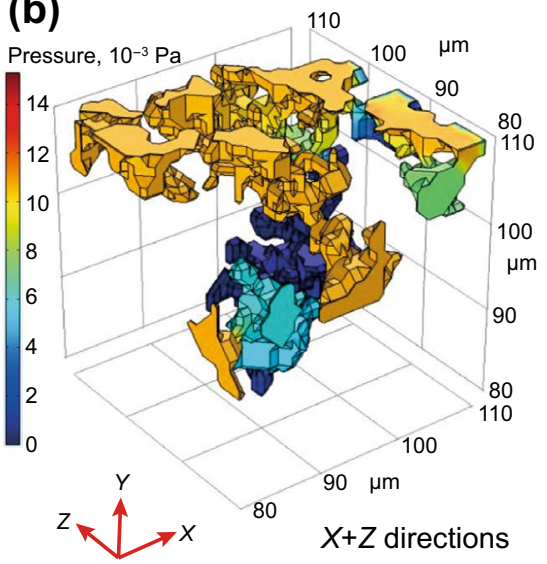

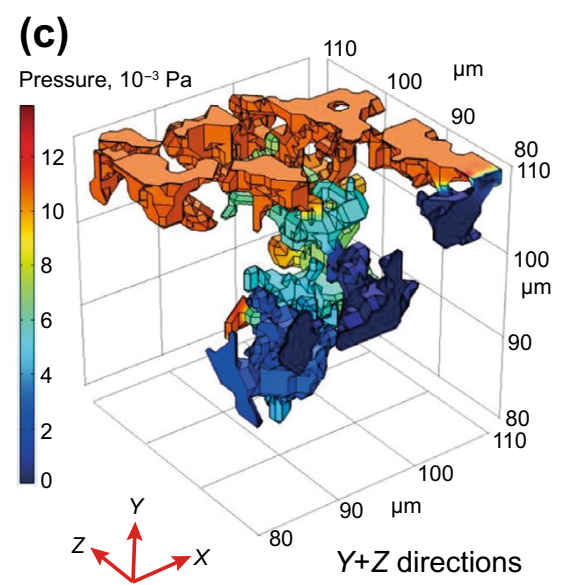

Fig. 17 Distributions of pressure field along dual-channels in $X+Y, X+Z$, and $Y+Z$ directions. Notes: $X$ and $Y$ direction means the direction horizontal to the bedding plane, and $Z$ direction means the direction perpendicular to the bedding plane

(a)

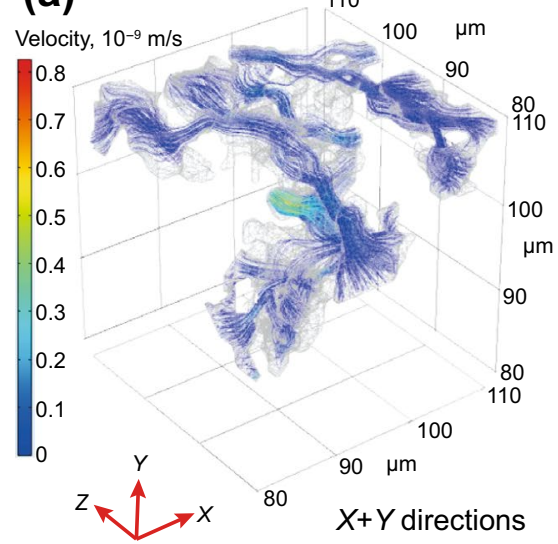

(b)
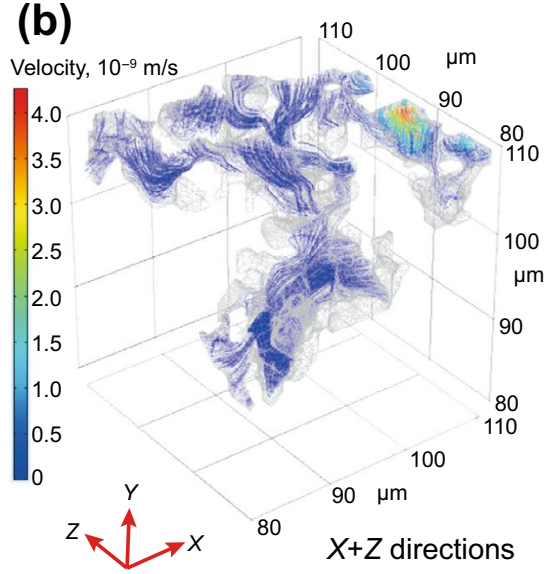

(c)

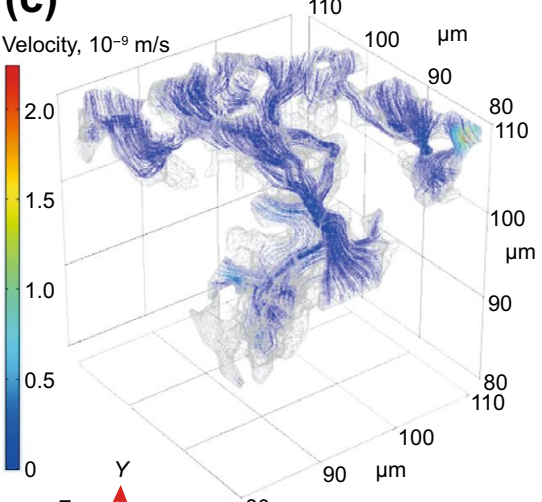

Fig. 18 Distributions of velocity field along dual-channels $X+Y, X+Z$, and $Y+Z$ directions. Notes: $X$ and $Y$ direction means the direction horizontal to the bedding plane, and $Z$ direction means the direction perpendicular to the bedding plane 

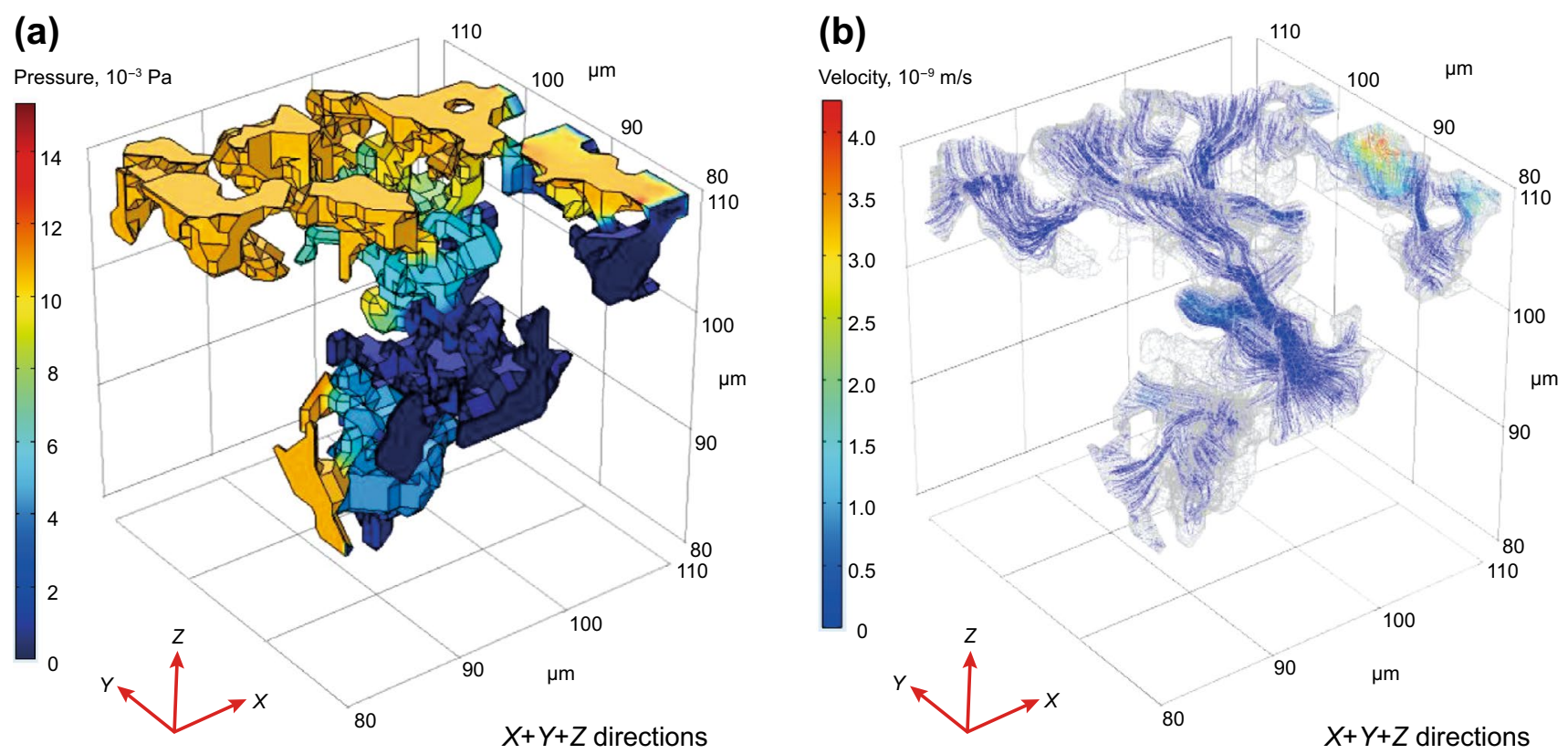

Fig. 19 Distributions of pressure field and velocity field in $X+Y+Z$ directions. a Pressure filed, $\mathbf{b}$ velocity filed. Notes: $X$ and $Y$ direction means the direction horizontal to the bedding plane, and $Z$ direction means the direction perpendicular to the bedding plane

gradually along the $\mathrm{CH}_{4}$ flow direction in the dual-channel and the multi-channel flow, and the maximum pressure occurs at the inlet boundary. Different from the pressure condition in the single-channel flow along the $X, Y$, and $Z$ directions, the distribution area of larger pressure in the dual-channel and the multi-channel flow is relatively wide (Figs. 17, 19a).

The mean flow velocity along the $X+Y, X+Z, Y+Z$ directions in the dual-channel flow, and along the $X+Y+Z$ directions in the multi-channel flow is $1.55 \times 10^{-11} \mathrm{~m} / \mathrm{s}$, $9.12 \times 10^{-11} \mathrm{~m} / \mathrm{s}, 1.94 \times 10^{-11} \mathrm{~m} / \mathrm{s}$, and $10.75 \times 10^{-11} \mathrm{~m} / \mathrm{s}$, respectively. Compared with the velocity condition in the single-channel flow along the $X, Y$, and $Z$ directions, the velocity increases obviously under the dual-channel and the multi-channel flow (Figs. 18, 19b), and the maximum velocity is nearly $4.31 \times 10^{-9} \mathrm{~m} / \mathrm{s}$ in the $X+Z$ and $X+Y+Z$ directions, which indicates that the development of interconnected pores with various directions is conducive to $\mathrm{CH}_{4}$ migration and production.

\subsection{Analysis of uncertainty}

The $3 \mathrm{D}$ reconstruction and visualization results of the macro-pores are more or less affected by the man-made differences in image processing, and the small sample size simulated will affect the simulation result of $\mathrm{CH}_{4}$ flow, but the real intention of this study is to analyze the $3 \mathrm{D}$ spatial structure of the macro-pores and $\mathrm{CH}_{4}$ flow simulation in anthracite coal based on $\mu$-CT scanning data.
In order to reduce the negative effect caused by the uncertainty, multiple methods should be used in conjunction during the $3 \mathrm{D}$ visualization and reconstruction processes of digital core. So, the optimal 3D reconstruction and visualization results can be obtained after image processing. Further improvement of the hardware equipment of the data processor can further expand the sample size simulated, so that the simulation effect of $\mathrm{CH}_{4}$ flow will be better.

\section{Conclusions}

In this study, the BF coal sample was firstly scanned by the $\mathrm{X}$-ray $\mu$-CT technology to obtain the 2D CT slices. Secondly, the original 2D CT slices were reconstructed and divided to obtain the pore network model. Then, a mathematical model of $\mathrm{CH}_{4}$ flow simulation with macro-pores as the carrier was established. Finally, the $\mathrm{CH}_{4}$ flow simulation and its visualization were realized based on the perfect docking of the X-ray $\mu$-CT technology and the COMSOL. The main conclusions are as follows:

1. The actual reconstructed volume of digital core is $250 \times 250 \times 250 \mu^{3}$, and the number of pores and throats gradually decreases with the increase of radius. The equivalent radius of pores and throats are 1-16 $\mu \mathrm{m}$ and $1.03-8.9 \mu \mathrm{m}$, respectively, and the throat length is $3.28-231.25 \mu \mathrm{m}$. The coordination number of pores concentrates around three, and the intersection point 
between the connectivity function and the $X$-axis is 3-4 $\mu \mathrm{m}$, which indicate the macro-pores have good connectivity in 3D space.

2. Regarding the single-channel flow, the pressure decreases gradually along the direction of $\mathrm{CH}_{4}$ flow. The $\mathrm{CH}_{4}$ firstly flows along the path with large radius and the short distance from the outlet. The flow velocity of $\mathrm{CH}_{4}$ gradually decreases from the center of the pore to the wall. Compared with the single-channel flow, the pressure also decreases gradually along the $\mathrm{CH}_{4}$ flow direction, while the velocity increases obviously in the dual-channel and multi-channel flow.

3. The mean flow pressure gradually decreases with the increase of the distance from the inlet slice. The change of mean flow pressure is relatively stable in the direction horizontal to the bedding plane, while it is relatively large in the direction perpendicular to the bedding plane. The mean flow velocity value in the direction horizontal to the bedding plane ( $Y$-axis) is the largest, followed by that in the direction horizontal to the bedding plane $(X$-axis), and the mean flow velocity value in the direction perpendicular to the bedding plane is the smallest, which is consistent with the distribution of mean flow pressure in different directions.

4. The perfect docking of the X-ray $\mu$-CT technology, the image processing technology and the COMSOL software can not only realize the $3 \mathrm{D}$ visualization reconstruction of pores and throats, but also complete the $\mathrm{CH}_{4}$ fluid simulation with the interconnected pores as the carrier. Multiple methods should be synthetically used during the 3D visualization and reconstruction processes of digital core, and the hardware equipment of the data processor should be further improved.

\footnotetext{
Acknowledgements We would like to express our gratitude to the two anonymous reviewers for offering their constructive suggestions and comments which improved this manuscript in many aspects. The work was financially supported by the National Key Research and Development Plan (No. 2018YFB0605601) and the National Natural Science Foundation of China (No. 41972168).
}

Open Access This article is licensed under a Creative Commons Attribution 4.0 International License, which permits use, sharing, adaptation, distribution and reproduction in any medium or format, as long as you give appropriate credit to the original author(s) and the source, provide a link to the Creative Commons licence, and indicate if changes were made. The images or other third party material in this article are included in the article's Creative Commons licence, unless indicated otherwise in a credit line to the material. If material is not included in the article's Creative Commons licence and your intended use is not permitted by statutory regulation or exceeds the permitted use, you will need to obtain permission directly from the copyright holder. To view a copy of this licence, visit http://creativecommons.org/licenses/by/4.0/.

\section{References}

Bird MB, Butler SL, Hawkes CD, et al. Numerical modeling of fluid and electrical currents through geometries based on synchrotron X-ray tomographic images of reservoir rocks using Avizo and COMSOL. Comput Geosci. 2014;73:6-16. https://doi. org/10.1016/j.cageo.2014.08.009.

Blunt MJ. Flow in porous media-pore-network models and multiphase flow. Curr Opin Colloid Interface. 2001;6(3):197-207. https://doi. org/10.1016/S1359-0294(01)00084-X.

Fang HH, Sang SX, Wang JL, et al. Simulation of paleotectonic stress fields and distribution prediction of tectonic fractures at the Hudi coal mine, Qinshui basin. Acta Geol Sin Engl. 2017;91(6):2007-23. https://doi.org/10.3969/j. issn.1000-9515.2017.06.005.

Fang HH, Sang SX, Liu SQ, et al. Study of digital petrophysical analysis method based on micro-focus X-ray tomography: a case study from No.3 coal seam of Bofang mining area in southern Qinshui basin. Coal Geol Explor. 2018;46(5):167-74 (in Chinese).

Fang HH, Sang SX, Liu SQ, et al. Experimental simulation of replacing and displacing $\mathrm{CH}_{4}$ by injecting supercritical $\mathrm{CO}_{2}$ and its geological significance. Int J Greenh Gas Control. 2019;81:115-25. https ://doi.org/10.1016/j.ijggc.2018.12.015.

Fu HJ, Tang DZ, Xu T, et al. Characteristics of pore structure and fractal dimension of low-rank coal: a case study of Lower Jurassic Xishanyao coal in the southern Junggar Basin, NW China. Fuel. 2017;193:254-64. https://doi.org/10.1016/j.fuel.2016.11.069.

Guo XB, Huang ZL, Zhao LB, et al. Pore structure and multi-fractal analysis of tight sandstone using MIP, NMR and NMRC methods: a case study from the Kuqa depression, China. J Pet Sci Eng. 2019;178:544-58. https://doi.org/10.1016/j.petrol.2019.03.069.

Hamamoto S, Moldrup P, Kawamoto K, et al. Pore network structure linked by X-ray CT to particle characteristics and transport parameters. Soils Found. 2016;56(4):676-90. https://doi.org/10.1016/j. sandf.2016.07.008.

Harpreet S. Representative elementary volume (REV) in spatio-temporal domain: a method to find REV for dynamic pores. J Earth Sci. 2017;28(2):391-403. https://doi.org/10.1007/s12583-017-0726-8.

Heriawan MN, Koike K. Coal quality related to microfractures identified by CT image analysis. Int J Coal Geol. 2015;140:97-110. https://doi.org/10.1016/j.coal.2015.02.001.

Herring AL, Harper EJ, Andersson L, et al. Effect of fluid topology on residual nonwetting phase trapping: implications for geologic $\mathrm{CO}_{2}$ sequestration. Adv Water Resour. 2013;62:47-58. https://doi. org/10.1016/j.advwatres.2013.09.015.

Hodot BB. Outburst of coal and coalbed gas. Beijing: China Industry Press; 1966.

Ju Y, Wang JB, Gao F, et al. Lattice-Boltzmann simulation of microscale $\mathrm{CH}_{4}$ flow in porous rock subject to force-induced deformation. Chin Sci Bull. 2014;59(22):2127-36 (in Chinese).

Lei J, Pan BZ, Zhang LH. Advance of microscopic flow simulation based on digital cores and pore network. Prog Geophys. 2018;33(2):653-60 (in Chinese).

Li ZW, Zhang GY. Fracture segmentation method based on contour evolution and gradient direction consistency in sequence of coal rock CT images. Math Probl Eng. 2019. https://doi. org/10.1155/2019/2980747.

Li CF, Fang Y, Ju YW. Three-dimensional reconstruction of coal's microstructure using randomly packing-sphere and pore-growing and lattice Boltzmann method. J Nanosci Nanotechnol. 2017;17(9):6867-72. https://doi.org/10.1166/jnn.2017.14437.

Li JJ, Liu Y, Gao YJ, et al. Pore-scale study of the pressure-sensitive effect of sandstone and its influence on multiphase flows. Pet Sci. 2019;16:382-95. https://doi.org/10.1007/s12182-018-0266-6. 
Lindquist WB, Venkatarangan A, Dunsmuir J, et al. Pore and throat size distributions measured from synchrotron $\mathrm{X}$ ray tomographic images of Fontainebleau sandstones. J Geophys Res Solid Earth. 2000;105:21509-27. https://doi.org/10.1029/2000JB900208.

Liu SQ, Sang SX, Wang G, et al. FIB-SEM and X-ray CT characterization of interconnected pores in high-rank coal formed from regional metamorphism. J Pet Sci Eng. 2017;148:21-31. https:// doi.org/10.1016/j.petrol.2016.10.006.

Liu SQ, Sang SX, Ma JS, et al. Three-dimensional digitalization modeling characterization of pores in high-rank coal in the southern Qinshui basin. Geosci J. 2019;23(1):175-88. https://doi. org/10.1007/s12303-018-0014-3.

Ma Y, Zhong NN, Huang XY, et al. The application of focused ion beam scanning electron microscope (FIB-SEM) to the nanometer-sized pores in shales. J Chin Electron Microsc Soc. 2014;3(33):251-6 (in Chinese).

Naveen P, Asif M, Ojha K. Integrated fractal description of nanopore structure and its effect on $\mathrm{CH}_{4}$ adsorption on Jharia coals, India. Fuel. 2018;232:190-204. https://doi.org/10.1016/j. fuel.2018.05.124.

Ni XM, Miao J, Lv RS, et al. Quantitative 3D spatial characterization and flow simulation of coal macro-pores based on $\mu \mathrm{CT}$ technology. Fuel. 2017;200:199-207. https://doi.org/10.1016/j. fuel.2017.03.068.

Rabbani A, Jamshidi S, Salehi S. An automated simple algorithm for realistic pore network extraction from micro-tomography images. J Pet Sci Eng. 2014;123:164-71. https://doi.org/10.1016/j.petro 1.2014.08.020.

Shaina K, Hesham ES, Carlos TV, et al. Assessing the utility of FIB-SEM images for shale digital rock physics. Adv Water Resour. 2016;95:302-16. https://doi.org/10.1016/j.advwa tres.2015.06.010.

Silin D, Patzek T. Pore space morphology analysis using maximal inscribed spheres. Physica A. 2006;371(2):336-60. https://doi. org/10.1016/j.physa.2006.04.048.

Sleutel S, Cnudde V, Masschaele B, et al. Comparison of different nano- and micro-focus X-ray computed tomography set-ups for the visualization of the soil microstructure and soil organic matter. Comput Geosci. 2008;34(8):931-8. https://doi.org/10.1016/j. cageo.2007.10.006.

Sok RM, Knackstedt MA, Sheppard AP, et al. Direct and stochastic generation of network models from tomographic images: effect of topology on residual saturations. Transp Porous Med. 2002;46:345-71. https://doi.org/10.1023/a:1015034924371.

Song WH, Yao J, Li Y, et al. New pore size distribution calculation model based on chord length and digital image. J Nat Gas Sci Eng. 2017;48:111-8. https://doi.org/10.1016/j.jngse.2016.12.041.

Su PH, Xia ZH, Wang P, et al. Fractal and multifractal analysis of pore size distribution in low permeability reservoirs based on mercury intrusion porosimetry. Energies. 2019;12(7):1337. https://doi. org/10.3390/en12071337.

Sun L, Wang XQ, Jin X, et al. Three dimensional characterization and quantitative connectivity analysis of micro/nano pore space. Pet Explor Dev. 2016;43(3):490-8. https://doi.org/10.1016/S1876 -3804(16)30063-5.

Vik B, Bastesen E, Skauge A. Evaluation of representative elementary volume for a vuggy carbonate rock-Part: porosity, permeability, and dispersivity. J Pet Sci Eng. 2013;112(3):36-47. https://doi. org/10.1016/j.petrol.2013.03.029.

Viljoen J, Campbell QP, Le RM, et al. An analysis of the slow compression breakage of coal using microfocus X-ray computed tomography. Int J Coal Prep Util. 2015;35(1):1-13. https://doi. org/10.1080/19392699.2014.907283.

Vogel HJ, Roth K. Quantitative morphology and network representation of soil pore structure. Adv Water Resour. 2001;24(3-4):23342. https://doi.org/10.1016/S0309-1708(00)00055-5.

Wang R, Sang SX, Zhu DD, et al. Pore characteristics and controlling factors of the Lower Cambrian Hetang Formation shale in Northeast Jiangxi, China. Energy Explor Exploit. 2018;36(1):43-65. https://doi.org/10.1177/0144598717723814.

Wolf KHAA, Bergen FV, Ephraim R, et al. Determination of the cleat angle distribution of the RECOPOL coal seams, using CTscans and image analysis on drilling cuttings and coal blocks. Int J Coal Geol. 2008;73(3):259-72. https://doi.org/10.1016/j. coal.2007.06.001.

Wu H, Yao YB, Zhou YF, et al. Analyses of representative elementary volume for coal using X-ray $\mu$-CT and FIB-SEM and its application in permeability predication model. Fuel. 2019a;254:115563. https://doi.org/10.1016/j.fuel.2019.05.146.

Wu H, Zhou YF, Yao YB, et al. Imaged based fractal characterization of micro-fracture structure in coal. Fuel. 2019b;239:53-62. https ://doi.org/10.1016/j.fuel.2018.10.117.

Xiong B, Liu K, Guo K, et al. Characterization of the physical properties of coal reservoirs in the western Guizhou and eastern Yun nan by X-ray computed tomography. Pet Geol Exp. 2016;38(3):40712 (in Chinese).

Yang YF, Liu ZH, Yao J, et al. Flow simulation of artificially induced microfractures using digital rock and Lattice Boltzmann methods. Energies. 2018;11(8):2145. https://doi.org/10.3390/en11082145.

Yao YB, Liu DM, Che Y, et al. Non-destructive characterization of coal samples from China using microfocus X-ray computed tomography. Int J Coal Geol. 2009a;80(2):113-23. https://doi. org/10.1016/j.coal.2009.08.001.

Yao YB, Liu DM, Tang DZ, et al. Fractal characterization of seepage-pores of coals from China: an investigation on permeability of coals. Comput Geosci. 2009b;35(6):1159-66. https://doi. org/10.1016/j.cageo.2008.09.005.

Youssef S, Rosenberg E, Gland NF et al. High resolution CT and porenetwork models to assess petrophysical properties of homogeneous and heterogeneous carbonates. In: SPE/EAGE reservoir characterization and simulation conference, Abu Dhabi, UAE (2007).

Yuan C, Chareyre B, Darve F. Pore-scale simulations of drainage in granular materials: finite size effects and the representative elementary volume. Adv Water Resour. 2015;95:109-24. https://doi. org/10.1016/j.advwatres.2015.11.018.

Zhao YX, Sun YF, Liu SM, et al. Pore structure characterization of coal by synchrotron radiation nano-CT. Fuel. 2018;215:102-10. https ://doi.org/10.1016/j.fuel.2017.11.014.

Zhao JL, Tang DZ, Qin Y, et al. Fractal characterization of pore structure for coal macrolithotypes in the Hancheng area, southeastern Ordos basin, China. J Pet Sci Eng. 2019;178:666-77. https://doi. org/10.1016/j.petrol.2019.02.060.

Zhou G, Zhang Q, Bai RN, et al. Characterization of coal micro-pore structure and simulation on the seepage rules of low-pressure water based on CT scanning data. Minerals. 2016;6(3):78. https ://doi.org/10.3390/min6030078.

Zhou SD, Liu DM, Cai YD, et al. Comparative analysis of nanopore structure and its effect on methane adsorption capacity of Southern Junggar coalfield coals by gas adsorption and FIB-SEM tomography. Microporous Mesoporous Mater. 2018;272:117-28. https://doi.org/10.1016/j.micromeso.2018.06.027. 